\title{
Management Scenarios of the Grand Ethiopian Renaissance Dam and Their Impacts under Recent and Future Climates
}

\author{
Stefan Liersch *(1), Hagen Koch (1) and Fred Fokko Hattermann \\ Potsdam Institute for Climate Impact Research (PIK), RD II Climate Impacts \& Vulnerabilities, \\ 14473 Potsdam, Germany; Hagen.Koch@pik-potsdam.de (H.K.); hattermann@pik-potsdam.de (F.F.H.) \\ * Correspondence: liersch@pik-potsdam.de; Tel.: +49-331-288-2487
}

Received: 7 August 2017; Accepted: 20 September 2017; Published: 22 September 2017

\begin{abstract}
Close to the border with Sudan, Ethiopia is currently building the largest hydroelectric power plant in Africa with a storage volume corresponding to approximately 1.5 years of the mean discharges of the Blue Nile. This endeavor is controversially debated in the public and the scientific literature. Contributing to this discussion, by shading some light on climate change issues, an eco-hydrological model, equipped with a reservoir module, was applied to investigate downstream hydrological impacts during filling and regular operation, the latter considering climate change projected by an ensemble of 10 global and regional climate models. Our results show that at the earliest after 20 months, the dam could produce hydroelectric power. Full supply level may be reached after four years or not at all, depending on filling policies and assumptions of seepage rates. Under recent hydro-climatic conditions, the dam may produce $13 \mathrm{TWh}^{-a}$, which is below the envisaged target of $15.7 \mathrm{TWh}^{-a}$. The ensemble mean suggests slightly increasing hydropower production in the future. Almost independently of the operation rules, the highly variable discharge regime will be significantly altered to a regime with almost equal flows each month. Achieving a win-win situation for all riparian countries requires a high level of cooperation in managing the Eastern Nile water resources.
\end{abstract}

Keywords: water resources management; Grand Ethiopian Renaissance Dam; Blue Nile; reservoir operation scenarios; climate change

\section{Introduction}

The Blue Nile River has its source in the Ethiopian Highlands in the Lake Tana catchment. These highlands are considered as the water tower of East Africa providing Ethiopia with an estimated hydropower potential of 45,000 MW [1], which is the second largest potential in Africa after the DR Congo. Yet, in 2001, only 3\% of this potential had been developed [2], and only 13\% of the Ethiopian households had access to electricity [3]. Due to an electricity access program, established in 2005, the number of households in rural towns and villages connected to the grid increased to over $40 \%$ in 2011 [1,3], but one year later, Ethiopia had $57 \mathrm{kWh}$ per capita and year, still at a very low consumption level, where the global average is $7000 \mathrm{kWh}$ per capita and year [4]. To meet the growing electricity demand that increased with improved access and challenged the provision, Ethiopia's power corporation commissioned three large hydropower plants in 2010 with a capacity above 2000 MW [1]. In the course of the Climate-Resilient Green Energy strategy, the Ethiopian Government is planning to expand its hydroelectric capacity further [5] and to become a regional power hub [1], by implementing several hydropower projects and building power transmission and distribution lines to neighboring countries [4]. A major step in this regard was the announcement in 2011 to construct the largest reservoir in Africa near the border to Sudan [6], the Grand Ethiopian Renaissance Dam (GERD), 
which will account for more than $40 \%$ of the installed generation capacity in the country [3] and may produce more electricity than Ethiopia can use in the medium term [7]. The GERD project, presumably finalized in the coming years, is supposed to support the economic development of Ethiopia, to secure the energy supply, to make Ethiopia less dependent on oil imports and to provide electricity to a number of neighboring countries [3]. To satisfy the firm energy requirements also during dry periods, the reservoir will have an over-year storage volume of about 74 billion $\mathrm{m}^{3}$ (BCM) [8], corresponding to about 1.5 years of the long-term mean discharges of the Blue Nile River.

The primary use of the GERD will be the generation of hydroelectric power, and therefore, the World Bank and other international donors have refused to support the project [5], because funding is normally granted for multi-purpose dams only and Ethiopia has failed to create partnerships with power companies in neighboring countries [9]. Hence, the Ethiopian Government mainly finances the construction by urging citizens and private companies to buy bonds to support the project [4,9-12], where turbines and technical equipment are financed by Chinese banks [9].

Like many large-scale projects, the GERD is subject to a number of concerns and criticism with regard to jeopardizing downstream water security and livelihoods [4], which created tension particularly between Egypt and Ethiopia [7]. The large capacity of the reservoir will certainly shift the geopolitical balance in the Eastern Nile Basin for which Egypt has fears about its water supply [6,13]. According to Beyene (2013) [14], the dam is oversized and will never produce what is being promised (6000 MW). During the filling period, it is assumed that water discharges to Egypt may be cut by $12-25 \%$ [15]. Other concerns are the lack of transparency of the planning process (quality of project documents) or issues not sufficiently considered or reported, such as dam safety, downstream changes of discharges, environmental impacts, climate risks, sediment and water quality issues and missing dam operation strategies [16].

As the completion of the dam construction is getting closer, more and more studies are being published that controversially discuss the likely consequences of the GERD on the environmental, economical, political and management issues [4,7,10,17-21]. Transboundary cooperation in managing the Eastern Nile water infrastructure to safeguard future water supply in the riparian countries seems to be the most important keyword in this connection. Where Sudan's interests may be largely aligned with Ethiopia, because regulated flows into Sudan are beneficial for hydropower generation, flood protection and irrigated agriculture (due to limited water storage capacities in Sudan) [20], it is important that Ethiopia agrees with Egypt and Sudan on rules during reservoir filling and operation, particularly during a sequence of drought years [7]. Many of the recent studies see large economic potential and benefits for all countries, or at least more pros than cons, once the GERD is online and on the condition that full cooperation is achieved $[4,7,10,20]$.

Although socio-political consequences, like the resettlement of people or potential conflicts among riparian countries, or engineering risks and hazards, like water quality or dam failures, are of outmost importance, these issues are not the subject of this study. The main purpose is to investigate the likely impacts of the GERD on downstream discharges during the filling process and under regular operation, the latter also under climate change projections using an ensemble of ten global and regional climate models. Moreover, five different reservoir operation strategies to generate hydropower are investigated once the reservoir is filled to a certain level. Reservoir filling strategies were recently analyzed by Zhang et al. [17] and Wheeler et al. (2016) [18], but regular operation rules were not investigated in either study. An assessment of the likely impacts of a dam such as the GERD, which is not in operation mode yet, comes along with a number of uncertainties. It is for instance unknown how the reservoir will be managed during the period of filling, at what filling state the dam becomes finally operational, if the system will be operated to maximize the generation of hydroelectric power or if release rules to preserve ecological targets downstream are considered, how the hydro-climatic boundary conditions will either challenge or facilitate the management during filling and regular operation and the amount of water lost via seepage and evaporation. 
Scenarios are thus the only suitable method to capture the range of uncertainties of these unknown variables in order to answer the following questions that are central to our research: (1) How will dam operations alter the natural flow regime (annual cycle) of the Blue Nile River? (2) What impacts on downstream discharges can be expected during the reservoir filling process? (3) What are the implications of different reservoir operation strategies for hydroelectric power generation assuming historical and future climatic conditions projected by an ensemble of ten climate models? By answering these questions, it is intended to provide some useful information on possible operation strategies that may reduce negative environmental impacts by satisfying water resources use of the involved countries of Ethiopia, Sudan and Egypt.

\section{Materials and Methods}

\subsection{Study Area}

The main focus of this study is on the GERD that is currently under construction and is located in Ethiopia at the Blue Nile River approximately $40 \mathrm{~km}$ upstream from the border to Sudan. The surface area of the reservoir will cover an area of about $1874 \mathrm{~km}^{2}$ with a length of $246 \mathrm{~km}$ at Full Supply Level (FSL) and an area of about $606 \mathrm{~km}^{2}$ at Minimum Operating Level (MOL) [8]. The maximal fall height will be $133 \mathrm{~m}$, and the maximum storage capacity amounts to $74 \mathrm{BCM}$, with an active storage volume of 59.22 BCM [8]. To investigate different filling and operation strategies and their impact on the downstream flow regime under recent and future climates, a semi-distributed eco-hydrological model was calibrated and validated for the Upper Blue Nile catchment (UBN) that simulates inflows into the GERD and includes a reservoir module to simulate filling and release processes. The Blue Nile River rises in Lake Tana in the Ethiopian Highlands, and the catchment area of the UBN delineated in this study covers an area of $172,000 \mathrm{~km}^{2}$ (see Figure 1). The flow regime of the UBN in Ethiopia is still largely natural with a high seasonal and inter-annual variability [20].

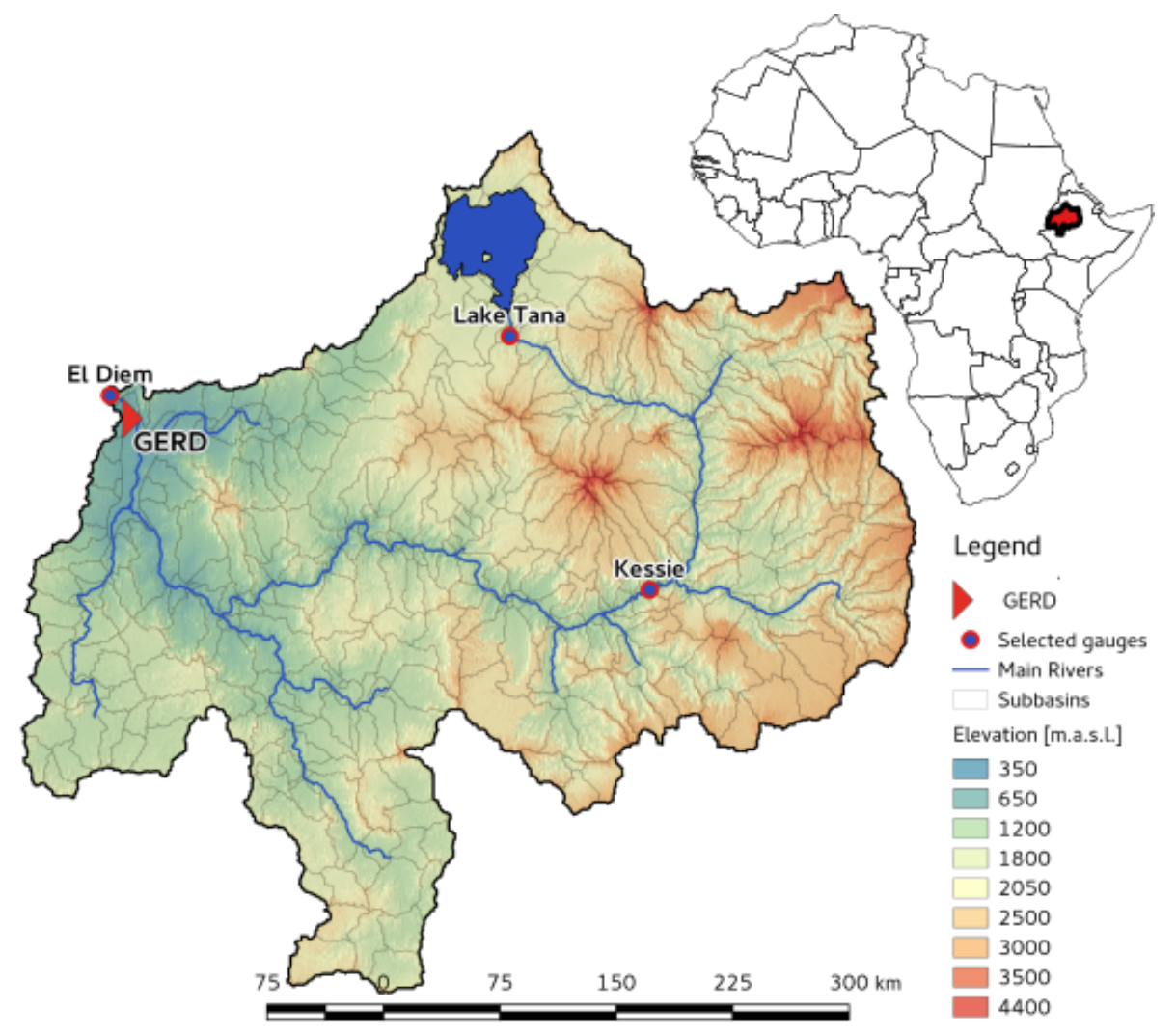

Figure 1. Map of the Upper Blue Nile catchment (UBN) in Ethiopia. 


\subsection{Data}

The data required to conduct the simulations in this study are data to parameterize the reservoir module with GERD characteristics and data to set up, calibrate and validate the hydrological model. The basic information about the dam and its reservoir properties were taken from the International Panel of Experts (IPoE 2013) [8] and are reported in Table S1 in the Supplement. Missing information not provided in the report are rating curves relating lake water level, volume and area. These values were derived from the SRTM digital elevation model [22] using the GRASS GIS module r.lake, which computes the water volume and flooded surface area at given water levels at a defined point, the GERD outlet in this case. Values in between the given water levels are linearly interpolated. The hydrological model requires daily weather data and information on soil properties, topography and land use/cover. The source of weather variables in the period 1960-1999, such as daily precipitation, temperature and solar radiation, are the gridded Watch Forcing Data (WFD) with a spatial resolution of 0.5 degrees [23], which are based on ERA40 reanalysis [24]. To delineate the UBN and its sub-basins, the SRTM DEM at 90-m horizontal resolution was used [22]. Soil properties were derived from the Harmonized World Soil Database [25], and information on land use/cover was taken from GLC2000 [26].

\subsection{Climate Models}

To investigate the potential impact of climate change on the management of the GERD, an ensemble of four downscaled and bias-corrected global Earth System Models (ESMs) and six Regional Climate Models (RCMs) was used (see Table S2 in the Supplement). The downscaling and bias-correction method applied to ESMs is described in Hempel et al. (2013) [27] and the method to bias-correct the Coordinated Regional Climate Downscaling Experiment (CORDEX) RCMs in Liersch et al. (2016) [28].

Four of the six RCMs in the ensemble used in this study are Bias-Corrected (BC) and two are Uncorrected (UC), because their performance was higher than their BC counterparts. Model performance is analyzed and their selection criteria described in Liersch et al. (2016) [28]. In this study, only climate projections of the Representative Concentration Pathway (RCP) 8.5 are used, because the change signals and magnitudes are more pronounced than in the other RCPs. According to van Vuuren et al. (2011) [29], RCP 8.5 represents the highest emission scenario with a rising radiative forcing pathway leading to $+8.5 \mathrm{~W} \cdot \mathrm{m}^{-2}$ and $\sim 1370 \mathrm{ppm} \mathrm{CO}_{2}$ eq by 2100 , where no stabilization in global GHG emissions is assumed.

\subsection{Hydrological Model}

The Soil and Water Integrated Model (SWIM) is a semi-distributed eco-hydrological model used to investigate the impacts of climate and land use changes on the water balance and the natural and cultivated vegetation in medium and large-scale river basins. SWIM was developed by Krysanova et al. (2005) [30] on the basis of the Soil and Water Assessment Tool (SWAT) [31] and MATSALU [32] models. An overview of worldwide SWIM applications is provided by Krysanova et al. (2015) [33]. It implements physics-based processes and empirical approaches. All hydrological, nutrient and vegetation processes are simulated at the daily time step at the smallest entity, the Hydrological Response Unit (HRU), representing areas with similar land use/cover and soil properties within each sub-basin. There is no lateral interaction between HRUs, but the area-weighted HRU fluxes are added at each sub-basin outlet and routed through the river network to the catchment's outlet. Potential evapotranspiration $E T_{p}$ can either be estimated in SWIM using the Priestley-Taylor method or the Turc-Ivanov approach [34], where the latter was applied in the study at hand. Actual evapotranspiration $E T_{a}$ on vegetated and bare land surfaces can be limited by soil water availability, while evaporation from an open water surface is assumed to be unlimited and therefore equals $E T_{p}$ (see Equations (1) and (2)): 


$$
\begin{array}{cl}
E T_{p}=0.0031 * c_{m o} *(R+209.4) *(T /(T+15)) & \mid T \geq 5{ }^{\circ} \mathrm{C} \\
E T_{p}=0.000036 *(25+T)^{2} *(100-r h) & \mid T<5{ }^{\circ} \mathrm{C}
\end{array}
$$

where $c_{m o}$ represent monthly correction factors (see Table 1 ), $R$ is the solar radiation in $\mathrm{J} / \mathrm{cm}^{2}, T$ is the mean daily air temperature in ${ }^{\circ} \mathrm{C}$ and $r h$ the relative humidity in $\%$.

Table 1. Monthly $E T_{p}$ correction factors.

\begin{tabular}{cccccccccccc}
\hline January & February & March & April & May & June & July & August & September & October & November & December \\
\hline 1.15 & 1.15 & 1.15 & 1.15 & 1.15 & 0.85 & 0.85 & 0.85 & 0.85 & 0.85 & 1.15 & 1.15 \\
\hline
\end{tabular}

\subsection{Reservoir Module}

Koch et al. (2013) [35] developed a reservoir module that is an integral component of the SWIM model. It simulates reservoir storage and release processes during filling and regular operation and allows one to compute Hydroelectric Power Production (HPP) and to investigate the impacts of different management strategies on downstream discharges. Two storage types are considered, the dead storage $D S$ and the active storage $A S$. The $D S$ is normally the unmanaged volume below the base outlet. The $A S$ is the reservoir volume that can be managed by active filling and release depending on its purpose. In the model, it is possible to define monthly thresholds of minimal flows to be released downstream during the filling of the DS and AS.

Three operation rules are implemented to manage downstream discharges of the reservoir. The first option allows one to operate a reservoir to release daily minimum discharges to meet environmental targets downstream. In the second option, daily release is based on firm energy yield of a hydropower plant where the release to produce the targeted energy is calculated depending on the actual water level. This rule was used to simulate the GERD. The third option was implemented to simulate discharges from a natural lake where the release depends on the current water level of the lake assuming a static outlet at a given elevation. This option was used to account for the storage effect of Lake Tana in the Blue Nile headwaters.

In order to simulate hydropower generation at the reservoir, some characteristics of the hydropower plant are required: head, turbine flow capacity, and the efficiency of the turbines. The daily HPP in kWh is calculated as follows:

$$
H P P=(\eta * \rho * Q * h * g) * 24 / 1000
$$

where $\eta$ is turbine efficiency (dimensionless), $\rho$ is the density of water $\left(\mathrm{g} \cdot \mathrm{cm}^{-3}\right), Q$ is discharge $\left(\mathrm{m}^{3} \cdot \mathrm{s}^{-1}\right)$ (considering the maximum turbine flow capacity), $h$ is the effective head $(\mathrm{m})$ and $g$ the acceleration due to gravity $\left(\mathrm{m} \cdot \mathrm{s}^{-2}\right)$.

The actual reservoir area, volume and water levels are changing on a daily basis depending on inflows, reservoir release and losses due to evapotranspiration, seepage and withdrawals. The latter is not accounted for in this study, assuming no losses via withdrawals for irrigation or other purposes, because related data are not reported in available documents and are officially not envisaged. Reservoir release is determined by operation rules that are defined separately for the filling period and regular operation. Actual evapotranspiration from the reservoir area $E T_{\text {Res }}$ is determined by the area-weighted sums of the lake's open water surface evaporation $E T_{p}$ and actual evapotranspiration from the land area $E T_{a}$ (not permanently inundated reservoir area). Both $E T_{p}$ and $E T_{a}$ depend on the actual filling state of the reservoir. The daily seepage rate is computed as a user-defined fraction of the current total storage volume. A share of the seepage volume can either contribute to shallow groundwater flows downstream of the reservoir or the total volume is allowed to percolate into the deep groundwater storage. 


\subsection{Scenarios}

Discharges released from a reservoir are determined by strategies during filling and regular operation. These strategies, in turn, depend on various factors, such as targets for HPP, inflows into the reservoir (depending on hydro-climatic conditions and upstream land and water management), losses by seepage, evapotranspiration from the reservoir area $E T_{\text {Res }}$ and withdrawals. In the case of the GERD, many of these variables are uncertain. Therefore, scenarios are employed to capture these uncertainties and to account for the interdependency of some processes. Reservoir storage losses via seepage and $E T_{\text {Res }}$ depend, for example, not only on environmental conditions, but also on operation rules. The higher the volumes kept in the storage, the larger is the lake's surface area and the higher the evaporative and seepage losses.

The seepage volume Seep is calculated based on a user-defined seepage rate $s r$ expressed as a fraction of the actual storage volume $V_{a c t}$.

$$
\text { Seep }=V_{\text {act }} * s r
$$

Low, medium and high seepage rates are represented by $s r=10^{-5}, s r=10^{-4}$ and $s r=10^{-3}$. The suffixes "01", "02" and "03" in the scenario names used in the following denote "low", "medium" and "high" seepage rates. The high seepage rate scenario was included, because Noureddin (2013) [13] assumes that, due to rock formations, seepage losses may amount to $25 \%$ of the actual storage volume.

The first set of scenarios is used to investigate the filling process under different assumptions of monthly minimal discharges to be released downstream, different seepage rates and whether the reservoir is filled during a wet or dry hydro-climatic period (see Section 2.6.1). The second set of scenarios investigates the impact of five operation strategies on downstream discharges and HPP once the GERD is online (see Section 2.6.2). Both applications, the filling and the operation scenarios, are based on hydro-climatic conditions in the period 1960-1999. The first year is used as a warm-up period for the hydrological model and is therefore not considered in the analyses.

\subsubsection{Filling Scenarios}

Three reservoir filling scenarios are considered where monthly minimal flows released downstream $Q_{\min }^{(m)}$ correspond to monthly $Q_{75}, Q_{50}$ and $Q_{25}$ discharges. The numbers in the subscript indicate monthly exceedance probabilities of $75 \%, 50 \%$ and $25 \%$ and were calculated based on simulated discharges at gauge El Diem in the period 1961-1999. Where average monthly volumes are released by the rule $Q \min _{(m)}=Q_{50}$, downstream discharges would be comparable to a hydrological drought occurring every fourth year if the $Q_{\min }^{(m)}=Q_{75}$ rule is applied. The time required to fill the reservoir would be shorter in the latter case and would be the longest with the $Q \min _{(m)}=Q_{25}$ rule.

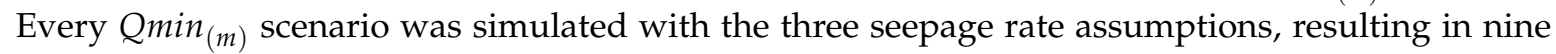
filling scenarios.

Due to the high seasonal and inter-annual variability of rainfall in the UBN, it matters whether the filling process would start in a wet or in a dry hydro-climatic period. Thus, the nine filling scenarios were simulated starting under wet (1960s) and dry (1980s) conditions.

\subsubsection{Operation Scenarios}

To investigate the likely impacts of the GERD on downstream discharges and HPP, five operation rules with different objectives were tested (see Figure S1 in the Supplement):

1. eco_mgt: Operation is aimed at representing the natural flow regime to a certain extent with peak flow during flood season (August) and lower flows in the dry season; if inflow and hence volume/water level are high, released discharges are also high; if reservoir volume is low, discharges and HPP are reduced depending on the season 
2. hpp_1500MW_a: Operation is aimed at HPP of $1500 \mathrm{MW}$ independent of season; if reservoir volume is low, released discharges and HPP are reduced depending on the season; only if AS is at full capacity, discharges and HPP are higher

3. hpp_1500MW_b: Operation is aimed at HPP of $1500 \mathrm{MW}$ if $A S<50 \%$; if reservoir volume is low, discharges and HPP are reduced depending on the season; increasing HPP if $A S>50 \%$, reaching $2100 \mathrm{MW}$ if full

4. hpp_1700MW: Operation is aimed at HPP of $1700 \mathrm{MW}$ independent of season; if reservoir volume is low, discharges and HPP are reduced depending on the season; only if AS is at full capacity, discharges and HPP are higher

5. hpp_1800MW: Operation is aimed at HPP of $1800 \mathrm{MW}$ independent of season or reservoir volume; only if $A S$ is at full capacity, discharges and HPP are higher

All operation scenarios were simulated with the three seepage assumptions, resulting in 15 operation scenarios. To assess the impact of the operation rules on the hydrological regime of the Blue Nile River, operation scenario discharges are compared with reference discharge simulations in the period 1961-1999. Changes of inter-annual variability and extremes are investigated by analyzing exceedance probabilities $E P$, such as $Q_{90}$ and $Q_{10}$ discharges. Alterations of the annual cycle of discharges are shown by using the Pardé coefficient $P C$, where mean monthly discharges $M Q_{m}$ are divided by the annual mean $M Q$.

$$
P C_{m}=\frac{M Q_{m}}{M Q}
$$

HPP potentials of the scenarios are described by the average annual production $H P P_{\text {mean }}$, firm energy yields considering daily EPS of $90 \%, 95 \%$ and $99 \%$, the standard deviation of daily HPP $S D_{H P P}$ and the coefficient of variation of daily HPP $C V_{H P P}$.

$$
C V_{H P P}=\frac{S D_{H P P}}{H P P_{\text {mean }}} * 100
$$

The hpp_1500MW_01a operation scenario is also analyzed using climate projections of the climate model ensemble in the period between 2020 and 2099.

\section{Results}

\subsection{Climate Model Performance}

The climate model ensemble used in this study shows a good performance considering average monthly precipitation and mean temperature inputs in the historical period. Figures 2 and 3 show that the ensemble median represents almost perfectly the climate input of WFD that was used to bias-correct the climate models and to calibrate and validate the hydrological model. The ensemble range is adequate for both variables.

However, deficits with regard to daily maxima or the number of rainy days, etc., and their impacts on discharge simulations are discussed in Liersch et al. (2016) [28]. 


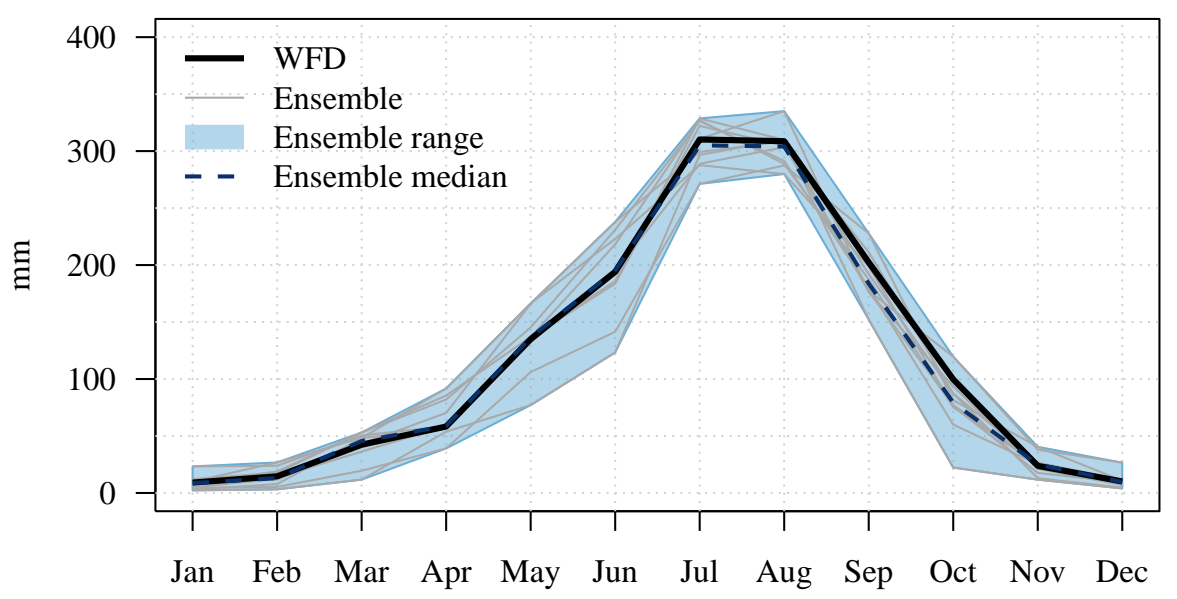

Figure 2. Average monthly precipitation in the historical period (1970-1999) of Watch Forcing Data (WFD) and the 10 climate models (ensemble) used in this study.

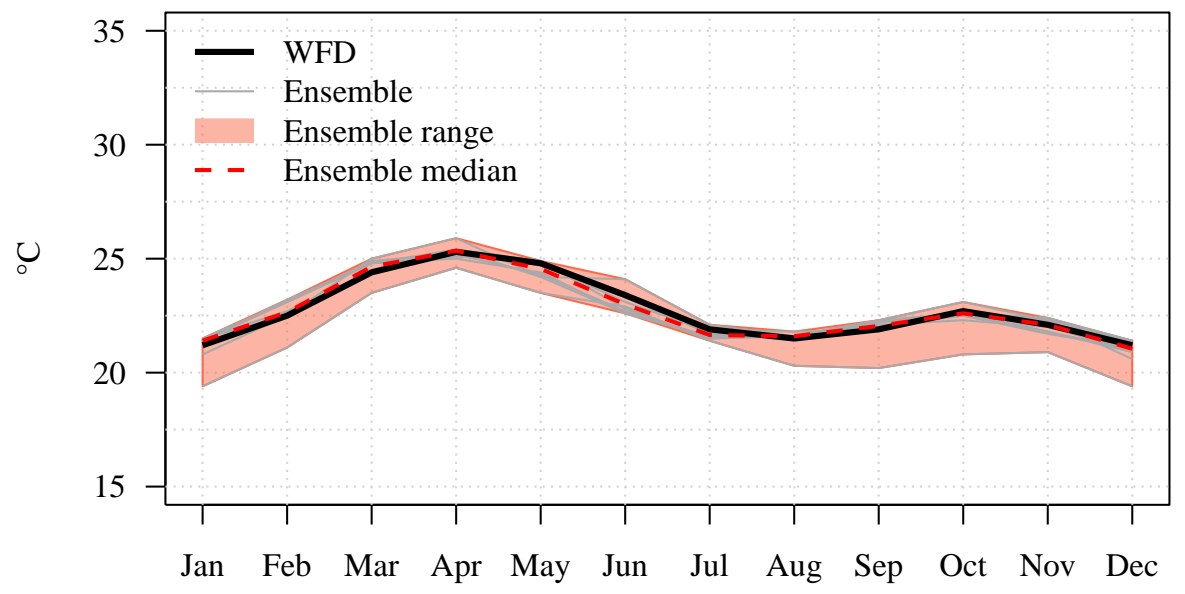

Figure 3. Average monthly mean air temperature in the historical period (1970-1999) of Watch Forcing Data (WFD) and the 10 climate models (ensemble) used in this study.

\subsection{Calibration and Validation}

The eco-hydrological model SWIM was calibrated (1981-1986) and validated (1987-1992) for the gauge El Diem and calibrated based on limited available discharge data at Lake Tana (1969-1975) and for the catchment defined at gauge Kessie (1976-1979) using WFD climate data. The locations of the gauges are shown in the case study map (Figure 1). The objective functions used to measure the performance of discharge simulations at the monthly time step are the coefficient of correlation $\left(R^{2}\right)$, the Nash-Sutcliffe Efficiency (NSE) [36] and the percent bias (PBIAS). Daily observed discharges were not available in this study. Note that the same model setup, only slightly re-calibrated for this study to achieve better PBIAS values, was already used by Liersch et al. (2016) [28] to assess the impacts of climate change and bias-correction on the hydrology in the UBN. The annual cycle is well represented in both periods with an average deviation of $-1.2 \%$ and $\mathrm{R}^{2}$ of 0.98 during calibration and a PBIAS of $-9.3 \%$ and $\mathrm{R}^{2}$ of 0.99 during validation; Figure $4 \mathrm{a}, \mathrm{c}$. In both cases, the model tends to slightly underestimate discharges after the peak in August. The performance of the monthly time series is very good in both periods ( $R^{2}$ of 0.95 and NSE of 0.89 ); see Figure $4 b$,d. Given this performance, the model can be expected to provide reliable discharge data as inputs to the GERD. Moreover, Figure S2 in the Supplementery Meterials shows that the model performs also well in the 1960s and 1970s, decades characterized by wetter hydro-climatic conditions than the period used to calibrate and validate the model. 

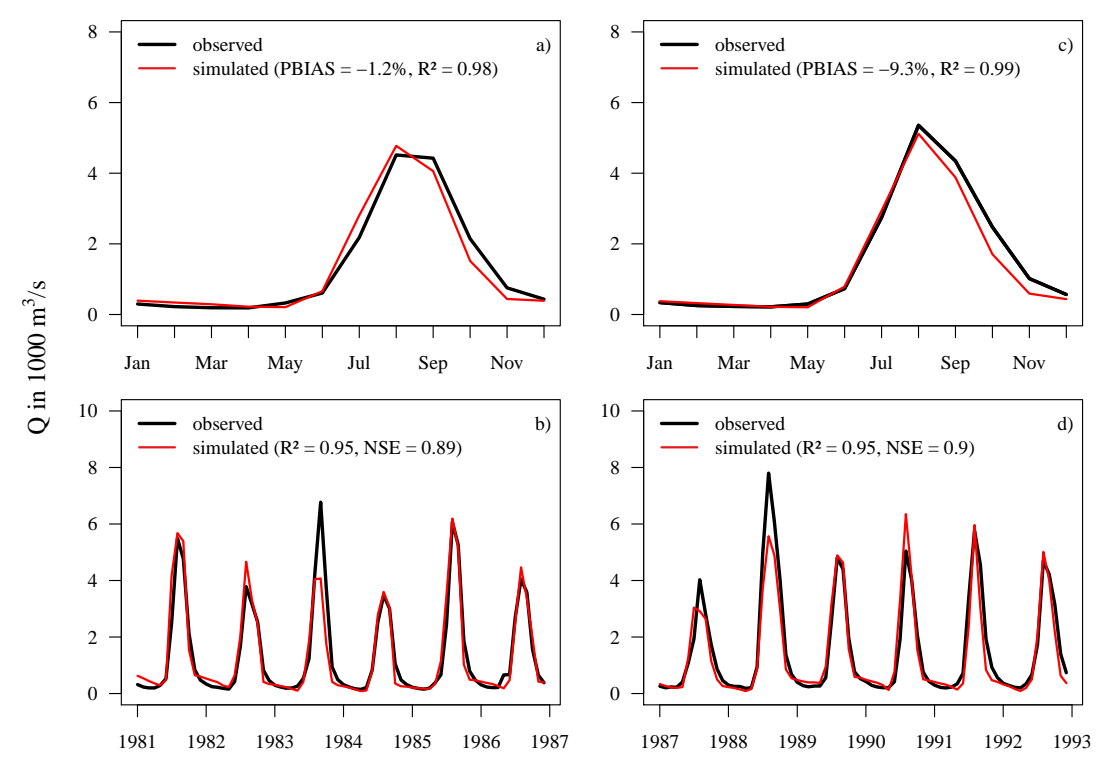

Figure 4. Annual cycle (top row) and monthly (bottom row) simulated discharges for calibration (a,b) and validation (c,d) periods at gauge El Diem (Sudan Border) using Watch Forcing Data (WFD).

\subsection{Reservoir Filling}

\subsubsection{Dead Storage}

Depending on monthly minimal flows to be released downstream $Q \min _{(m)}$ and considering the losses by $E T_{\text {Res }}$ and seepage, the time required to fill the $D S$ of the reservoir (14.8 BCM) is between eight months and 2.6 years under wet hydro-climatic conditions and up to almost eight years under dry conditions. The losses from the reservoir storage as percentage of average annual inflows via seepage can range between $0.1 \%$ and $32 \%$ and between $6.5 \%$ and $8.7 \%$ from $E T_{\text {Res }}$. Corresponding values are provided in Table 2 . Note that the seepage rate is only a scenario assumption used to account for the uncertainties of this unknown variable.

\subsubsection{Active Storage}

Once the $D S$ is filled, the filling of the $A S(59.2 \mathrm{BCM}$ ) starts. Figure 5 shows the 18 filling scenarios of the AS. The nine scenarios starting under wet hydro-climatic conditions are shown in blueish colors and the nine scenarios starting under dry conditions in reddish colors. As it is unknown at what filling state or operation level the reservoir will be taken into regular operation, the figure provides the point in time (in years) when the $A S$ achieves a certain percentage of filling for each scenario. The time required to fill the $D S$ is included here.

On condition that average annual discharges released downstream would be comparable to a drought occurring every fourth year $\left(Q_{\min }(m)=Q_{75}\right)$ and assuming low seepage rates under wet hydro-climatic conditions, the minimal time required to reach an operation level would be 1.6 years (1.9 years) assuming $30 \%$ or $(50 \%)$ of $A S$ filling. If the filling process would start under dry hydro-climatic conditions, it may take up 2.6 years to reach $50 \%$ filling. Assuming high seepage rates, the time to fill the $A S$ ranges between 1.7 years ( 2.7 years) under wet hydro-climatic conditions and 4.7 years ( 8.6 years) if the filling process would start under dry conditions (see Table 2, columns entitled $O p_{30 \%} O p_{50 \%}$ ).

If average monthly discharges $\left(\mathrm{Qmin}_{(\mathrm{m})}=Q_{50}\right)$ would be released during the filling process, the GERD could reach its operation level earliest after 3.6 years (assuming low seepage rates and wet conditions and $O p_{30 \%}$ ), after 7.5 years (assuming medium seepage rates and $O p_{50 \%}$ ) or after almost 20 years assuming high seepage rates (under dry hydro-climatic conditions and $O p_{30 \%}$ ). 
Table 2. Reservoir statistics during filling ( $O p=x \%$ of AS filled).

\begin{tabular}{|c|c|c|c|c|c|c|c|}
\hline Scenario & $\begin{array}{c}\text { DS Full } \\
\text { (Months (Years)) }\end{array}$ & $\begin{array}{c}O p_{50 \%} \\
\text { (Months (Years)) }\end{array}$ & $\begin{array}{c}O p_{30 \%} \\
\text { (Months (Years)) }\end{array}$ & $\begin{array}{l}\quad \text { Seep } \\
\text { (\% Inflow) }\end{array}$ & $\begin{array}{c}E T_{\text {Res }} \\
\text { (\% Inflow) }\end{array}$ & $\begin{array}{l}\text { In-Out } \\
\text { (BCM) }\end{array}$ & $\begin{array}{c}\text { In-Out } \\
\text { (\% Inflow) }\end{array}$ \\
\hline \multicolumn{8}{|c|}{ wet period Start in 1961} \\
\hline Seep_01_Q 75 & $7.9(0.7)$ & $23.3(1.9)$ & $18.7(1.6)$ & 0.4 & 7.4 & 8.6 & 16.3 \\
\hline Seep_01_Q $Q_{50}$ & $18.0(1.5)$ & $55.0(4.6)$ & $43.8(3.6)$ & 0.3 & 7.1 & 8.4 & 15.9 \\
\hline Seep_01_Q 25 & $29.8(2.5)$ & - & - & 0.1 & 6.5 & 2.6 & 4.9 \\
\hline Seep_02_Q $Q_{75}$ & $8.0(0.7)$ & $30.1(2.5)$ & $19.3(1.6)$ & 10.7 & 7.3 & 13.7 & 25.9 \\
\hline Seep_02_Q $Q_{50}$ & $18.3(1.5)$ & $90.5(7.5)$ & $45.3(3.8)$ & 6.3 & 6.9 & 9.4 & 17.7 \\
\hline Seep_02_Q $Q_{25}$ & $30.1(2.5)$ & - & - & 2.8 & 6.5 & 4.0 & 7.5 \\
\hline Seep_03_Q $Q_{75}$ & $8.0(0.7)$ & $31.9(2.7)$ & $20.1(1.7)$ & 32.0 & 7.2 & 23.2 & 43.8 \\
\hline Seep_03_Q $Q_{50}$ & $19.2(1.6)$ & - & - & 12.9 & 6.6 & 10.0 & 18.8 \\
\hline Seep_03_Q $Q_{25}$ & $31.4(2.6)$ & - & - & 8.2 & 6.4 & 6.7 & 12.7 \\
\hline \multicolumn{8}{|c|}{ dry period Start in 1981} \\
\hline Seep_01_Q 75 & $7.5(0.6)$ & $31.5(2.6)$ & $19.0(1.6)$ & 0.4 & 8.7 & 8.6 & 19.5 \\
\hline Seep_01_Q $Q_{50}$ & $8.2(0.7)$ & 233.5 (19.5) & $104.2(8.7)$ & 0.1 & 7.8 & 4.6 & 10.3 \\
\hline Seep_01_Q 25 & $43.2(3.6)$ & - & - & 0.1 & 7.7 & 2.9 & 6.7 \\
\hline Seep_02_Q $Q_{75}$ & $7.5(0.6)$ & $43.4(3.6)$ & $19.6(1.6)$ & 11.2 & 8.6 & 13 & 29.4 \\
\hline Seep_02_Q $Q_{50}$ & $8.2(0.7)$ & $236.6(19.7)$ & $224.2(18.7)$ & 4.0 & 7.8 & 5.5 & 12.4 \\
\hline Seep_02_Q 25 & $55.2(4.6)$ & - & - & 2.9 & 7.6 & 4.0 & 9.0 \\
\hline Seep_03_Q 75 & $7.5(0.6)$ & $103.4(8.6)$ & $56.0(4.7)$ & 23.6 & 8.2 & 16.7 & 37.9 \\
\hline Seep_03_Q & $8.6(0.7)$ & - & $237.5(19.8)$ & 10.9 & 7.7 & 7.5 & 16.9 \\
\hline Seep_03_Q 25 & $93.0(7.8)$ & - & - & 7.4 & 7.5 & 5.7 & 13.0 \\
\hline
\end{tabular}


An operation level of $30 \%$ of $A S$ filling would not be reached after 20 years in any scenario where minimal discharges to be released downstream correspond to $\operatorname{Qmin}_{(m)}=Q_{25}$. Hence, the most limiting factor for reservoir filling is $\operatorname{Qmin}_{(m)}$.

Full Supply Level (FSL) can be achieved earliest after 3.8 years on condition that $Q \min _{(m)}=Q_{75}$ with low or medium seepage rates during a wet period. According to Wheeler et al. (2016) [18], the earliest time when FSL may be reached is during the flood of the third year of the filling process. However, with $Q_{\min }^{(m)}=Q_{50}$, it may take up to 11 years, and with a release rule where $\operatorname{Qmin}_{(m)}=Q_{25}$, FSL is never reached at all within 20 years (see Figure 5).

The last two columns in Table 2 (In-Out) indicate the deviation between average annual inflows and outflows in the first ten years of the filling period. In some scenarios, the values are influenced by regular operation if the operation level of $50 \%$ was reached before the end of the tenth year. The results show that the reduction in flows can be a large fraction of inflows ranging between $5 \%$ and $44 \%$. Comparably low values (5-13\%) occur only in $\operatorname{Qmin}_{(\mathrm{m})}=Q_{25}$ scenarios where an operation level of $50 \%$ is never reached. With the $\operatorname{Qmin}_{(\mathrm{m})}=Q_{50}$ release rule, reservoir outflows would be reduced by $10-19 \%$ during the filling period.

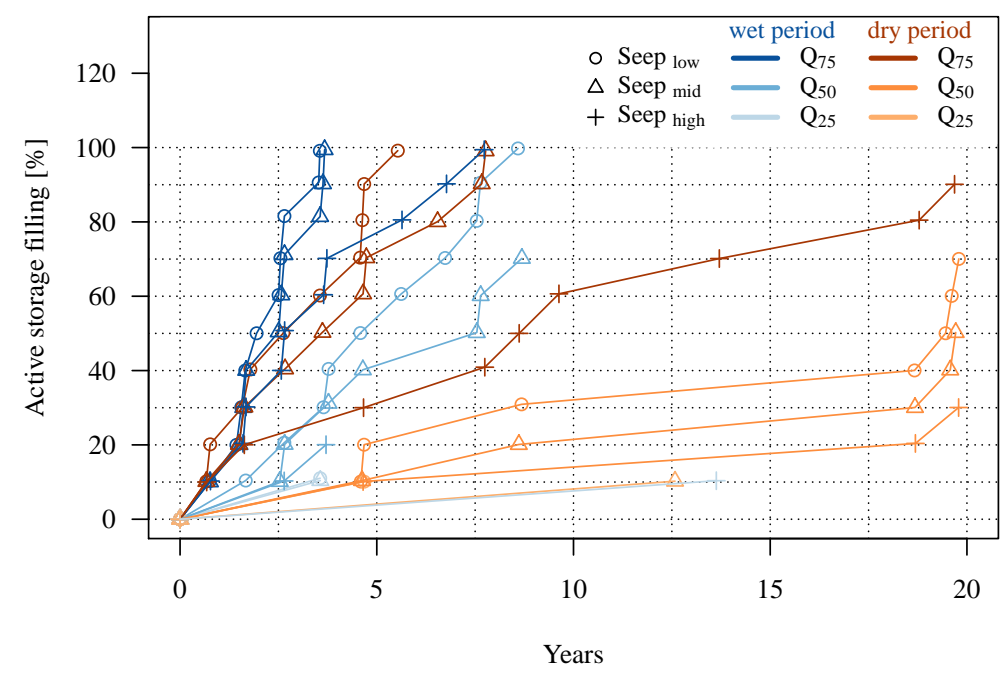

Figure 5. Time required to fill the active storage of the Grand Ethiopian Renaissance Dam (GERD) for different filling scenarios.

\subsection{Reservoir Operations}

\subsubsection{Impacts on Discharges}

Dam operation strategies can have major impacts on seasonal discharge patterns, particularly in simple pluvial regimes like the Blue Nile River, characterized by one peak discharge season and a low flow period. Figure 6a shows the impact of the operation scenarios on the annual cycle of discharges using Pardé coefficients (Equation (5)) and on average monthly discharges for scenarios with low seepage rates (Figure 6b). Unsurprisingly, all HPP scenarios show an increase of discharges during the dry period (November-May) of up to $300 \%$ (from around $500-1500 \mathrm{~m}^{3} \cdot \mathrm{s}^{-1}$ ) and a decrease of average monthly discharges during the rainy season from maximal $5200 \mathrm{~m}^{3} \cdot \mathrm{s}^{-1}$ down to $1500 \mathrm{~m}^{3} \cdot \mathrm{s}^{-1}$ in August, where discharges are used to re-fill the reservoir. Due to the large over-year storage capacity of the GERD, the reservoir could be managed in such a way as to release almost the same amount of water during each month of the year. This would change the highly seasonal and natural discharge regime into a completely balanced system (HPP scenarios). Exceptions where discharges higher or lower than the $M Q$ are released can either occur during wet periods when the reservoir is already at FSL and the flood peak is directly routed through the reservoir or during consecutive drought years when the water level drops significantly. Only the eco_mgt scenario preserves the annual cycle in a 
certain way, although discharges during the low flow period would increase considerably by about $100 \%$ (from $500-1000 \mathrm{~m}^{3} \cdot \mathrm{s}^{-1}$ ) and the peak in August would be reduced from $5200 \mathrm{~m}^{3} \cdot \mathrm{s}^{-1}$ to about $2900 \mathrm{~m}^{3} \cdot \mathrm{s}^{-1}$ and shifted to September.
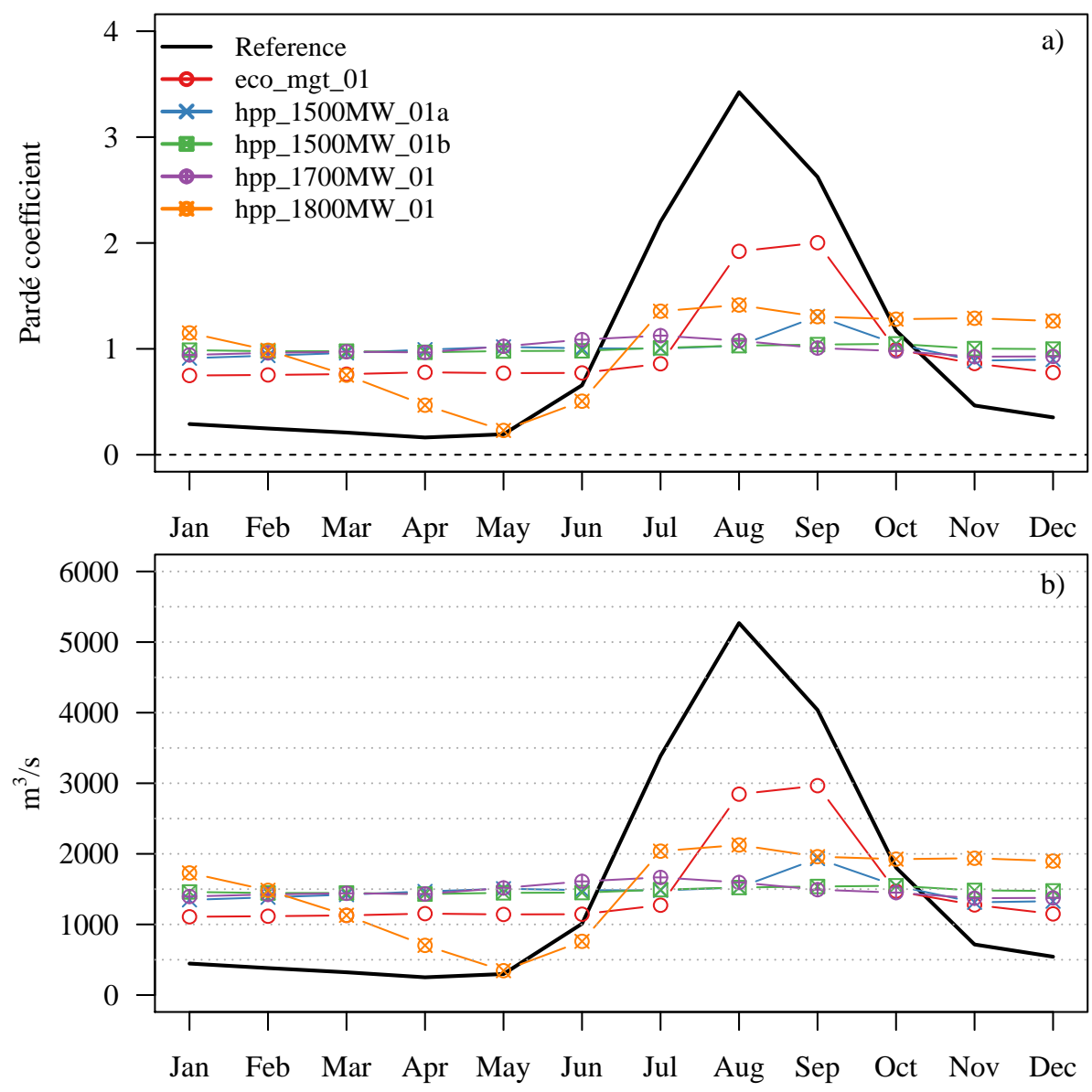

Figure 6. Pardé coefficients (a) and average monthly discharges (b) during 1961-1999.

Furthermore, the GERD will reduce the inter-annual variability of discharges. Given the huge capacity of the GERD, this is not surprising. The most obvious simulation result is that years with high $M Q s$ decrease significantly, where the higher the seepage rates, the stronger the decrease (Figure 7). The hpp_1800MW scenarios are an exception here. Assuming low seepage rates, years with low and extremely low MQs would occur less often. However, in the case of the medium and high seepage rate scenarios, years with low $M Q s$ are very likely to increase and are thus indicating a high sensitivity to seepage losses, which are not considered in other studies.

Besides the reduced inter-annual variability, daily dynamics are also significantly impacted. The $Q_{90}$ discharges (low flows) will increase from about $230 \mathrm{~m}^{3} \cdot \mathrm{s}^{-1}$ to $800-1250 \mathrm{~m}^{3} \cdot \mathrm{s}^{-1}$ and $Q_{10}$ (high flows) decrease from $4500 \mathrm{~m}^{3} \cdot \mathrm{s}^{-1}$ to $1450-2900 \mathrm{~m}^{3} \cdot \mathrm{s}^{-1}$ in all scenarios, except in the hpp_1800MW scenarios, where the low flow index is lower than in the baseline simulation; see Table 3 .

The impact of the GERD on the quantity of discharges released downstream is determined by losses via seepage and $E T_{\text {Res }}$. The evaporative losses from the reservoir surface area are on average $5.6 \mathrm{~mm}^{-d}$ in the reference period, which amounts to approximately $2044 \mathrm{~mm}^{-a}$. Relative to the volumes flowing into the GERD, these losses correspond to $7.3-7.9 \%$ (see Table 3). In the most optimistic case, the total losses $\left(E T_{\text {Res }}+\right.$ Seep $)$ might be around $8 \%$ of average inflows, but could amount to almost $33 \%$ considering high seepage losses. Assuming medium seepage rates, the total losses would amount to about $15-16 \%$ of inflows. Rainfall onto the reservoir's surface area contributes with $2.2 \mathrm{BCM}^{-a}$ to the climatic water balance $(\mathrm{CWB})$, reducing the losses from the storage considerably. 
In the annual average, the $C W B$ is $-1.6 \mathrm{BCM}^{-a}$ corresponding to $3.4 \%$ of inflows. Hence, the GERD would reduce the $M Q$ s by $3.4 \%$, not including the losses by seepage. In the worst case, the total losses may constrain dam operation strategies and should therefore not be neglected as a possible scenario.

Over the simulation period with reference climate of the years 1961-1999, the percentage of time (days) where the $A S$ is filled by $50 \%$ or more during regular operation is between $32 \%$ (eco_mgt_01) and 53\% (hpp_1500MW_01a) assuming low seepage rates; meaning the reservoir is on average hardly half-full or half-empty, respectively.

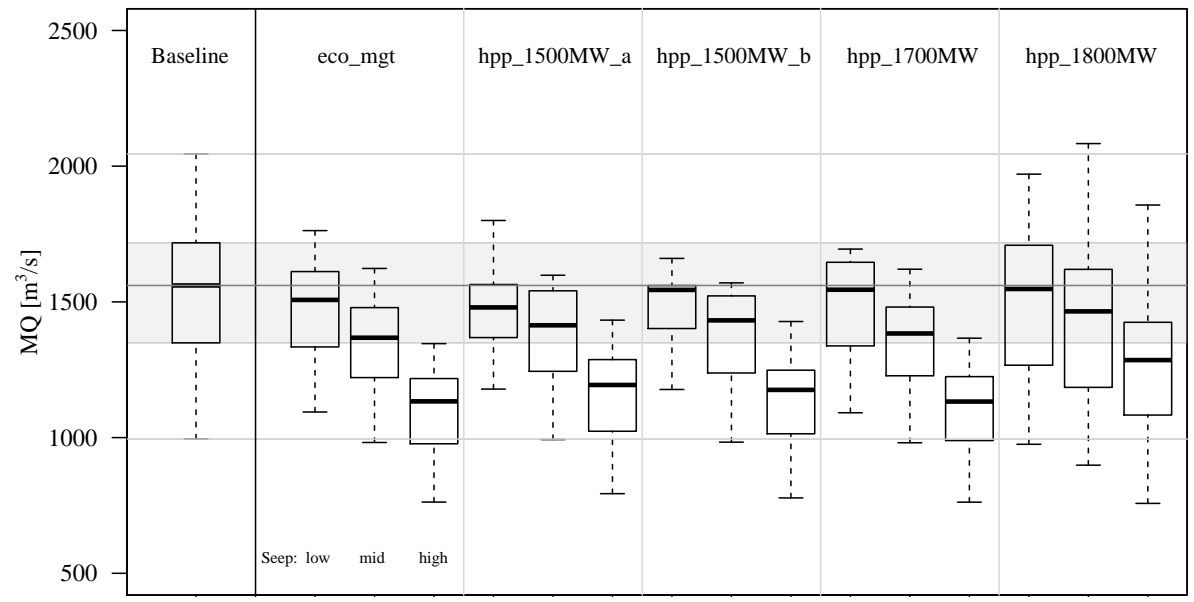

Figure 7. Inter-annual variability of $M Q$ for scenarios with low seepage rates for the period of 1961-1999.

Table 3. Reservoir statistics during operation from 1961-1999.

\begin{tabular}{|c|c|c|c|c|c|c|}
\hline \multirow[t]{2}{*}{ Scenario } & \multirow{2}{*}{$\begin{array}{c}\text { Storage }{ }^{1)} \\
{[\%]} \\
A S_{50}\end{array}$} & \multicolumn{2}{|c|}{$\begin{array}{c}\text { Discharge } \\
{\left[\mathrm{m}^{3} \cdot \mathrm{s}^{-1}\right]}\end{array}$} & \multicolumn{3}{|c|}{$\begin{array}{c}\text { Losses } \\
{[\% \text { Inflow] }}\end{array}$} \\
\hline & & $Q_{90}$ & $Q_{10}$ & Seep & $E T_{\text {Res }}$ & Total \\
\hline Baseline & - & 234 & 4508 & - & - & - \\
\hline eco_mgt_01 & 32 & 910 & 2858 & 0.3 & 7.8 & 8.1 \\
\hline eco_mgt_02 & 22 & 807 & 2726 & 8.7 & 7.7 & 16.4 \\
\hline eco_mgt_03 & 7 & 576 & 2423 & 25.3 & 7.6 & 32.9 \\
\hline hpp_1500MW_01a & 53 & 1261 & 1707 & 0.4 & 7.9 & 8.3 \\
\hline hpp_1500MW_02a & 11 & 1033 & 1705 & 7.3 & 7.6 & 14.9 \\
\hline hpp_1500MW_03a & 3 & 805 & 1460 & 22.0 & 7.5 & 29.5 \\
\hline hpp_1500MW_01b & 49 & 1231 & 1671 & 0.3 & 7.9 & 8.2 \\
\hline hpp_1500MW_02b & 18 & 1020 & 1605 & 7.9 & 7.7 & 15.5 \\
\hline hpp_1500MW_03b & 6 & 759 & 1477 & 23.1 & 7.6 & 30.7 \\
\hline hpp_1700MW_01 & 34 & 1128 & 1761 & 0.3 & 7.8 & 8.1 \\
\hline hpp_1700MW_02 & 23 & 1023 & 1633 & 8.4 & 7.7 & 16.1 \\
\hline hpp_1700MW_03 & 11 & 786 & 1447 & 25.0 & 7.6 & 32.6 \\
\hline hpp_1800MW_01 & 1 & 154 & 2192 & 0.2 & 7.3 & 7.5 \\
\hline hpp_1800MW_02 & 0 & 81 & 2202 & 5.1 & 7.3 & 12.4 \\
\hline hpp_1800MW_03 & 0 & 0 & 2187 & 15.7 & 7.3 & 23.0 \\
\hline
\end{tabular}

Notes: $01=$ low; $02=$ medium; 03 = high seepage rates. ${ }^{1)} \%$ of days where $A S$ is at least half full.

\subsubsection{Hydropower Production}

The envisaged electricity generation of the GERD is $15,692 \mathrm{GWh}^{-a}$ with an installed capacity of $6000 \mathrm{MW}$ to generate peak power $[8,18]$. To meet this electricity target, $1817 \mathrm{MW}$ would have to be produced on average.

Table 4 and Figures 8 and 9 show characteristics of HPP applying the five operation rules and assuming three seepage rate scenarios. The first column in Table 4 shows the average production in 
$\mathrm{GWh}^{-a}$ and MW in the period 1961-1999. The second and third columns indicate the variation of the $H P P$ time series using the standard deviation $S D_{H P P}$ and the coefficient of variation $C V_{H P P}$. The last three columns characterize the level of firm energy yields assuming exceedance probabilities $(E P)$ of $90 \%, 95 \%$ and $99 \%$ of the daily HPP time series. For the wet and dry hydro-climatic conditions, the data are shown in Tables S3 and S4 in the Supplement.

Table 4. HPP statistics during operation from 1961-1999.

\begin{tabular}{|c|c|c|c|c|c|c|}
\hline \multirow{2}{*}{ Scenario } & \multirow{2}{*}{$\begin{array}{c}H_{P P_{\text {mean }}} \\
\left(\mathrm{GWh}^{-\mathbf{a}}(\mathrm{MW})\right)\end{array}$} & \multirow{2}{*}{$\begin{array}{l}S D_{H P P} \\
\text { (MW) }\end{array}$} & \multirow[t]{2}{*}{$C V_{H P P}$} & \multicolumn{3}{|c|}{ Firm Yield (MW) } \\
\hline & & & & $E P_{90}$ & $E P_{95}$ & $E P_{99}$ \\
\hline eco_mgt_01 & $12,898(1472)$ & 717 & 49 & 838 & 770 & 602 \\
\hline eco_mgt_02 & $11,624(1327)$ & 700 & 53 & 730 & 643 & 496 \\
\hline eco_mgt_03 & $9190(1049)$ & 660 & 63 & 496 & 412 & 306 \\
\hline hpp_1500MW_01a & $13,037(1488)$ & 464 & 31 & 1104 & 1006 & 801 \\
\hline hpp_1500MW_02a & $11,079(1265)$ & 245 & 19 & 884 & 764 & 666 \\
\hline hpp_1500MW_03a & $9102(1039)$ & 260 & 25 & 665 & 557 & 406 \\
\hline hpp_1500MW_01b & $13,021(1486)$ & 276 & 19 & 1092 & 948 & 757 \\
\hline hpp_1500MW_02b & $11,300(1290)$ & 257 & 20 & 889 & 765 & 622 \\
\hline hpp_1500MW_03b & $9155(1045)$ & 303 & 29 & 624 & 513 & 380 \\
\hline hpp_1700MW_01 & $12,696(1449)$ & 260 & 18 & 1052 & 974 & 787 \\
\hline hpp_1700MW_02 & $11,429(1305)$ & 263 & 20 & 930 & 832 & 675 \\
\hline hpp_1700MW_03 & $9082(1037)$ & 278 & 27 & 671 & 557 & 419 \\
\hline hpp_1800MW_01 & $11,282(1288)$ & 700 & 54 & 91 & 39 & 0 \\
\hline hpp_1800MW_02 & $10,662(1217)$ & 737 & 61 & 46 & 0 & 0 \\
\hline hpp_1800MW_03 & $9375(1070)$ & 797 & 74 & 0 & 0 & 0 \\
\hline
\end{tabular}

Notes: $01=$ low; $02=$ medium; 03 = high seepage rates.

In scenarios with similar seepage rates, the operation rules do not have significant impacts on average HPP. In the case of low seepage rates, the annual HPP is around $13 \mathrm{GWh}^{-a}$ in all scenarios and between 11 and $11.5 \mathrm{GWh}^{-a}$ assuming medium seepage rates. The hpp_1800MW scenarios are an exception. From an economic or engineering perspective, continuity (variability) and reliability (firm yields) of electricity supply are usually more important than average annual HPP. Taking these indicators into account, the operation rules have a large impact on the performance of HPP.

Although average HPP is comparable among the scenarios, the eco_mgt and the hpp_1800MW scenarios show much higher variations throughout the year with standard deviations $>0.5 * H P P_{\text {mean }}$ and considerably lower $E P$ values. The highest $E P$ values are achieved in the hpp_1500W_01a scenario with an $E P_{99}$ of $801 \mathrm{MW}$, meaning that a daily minimal production of $801 \mathrm{MW}$ is guaranteed for $99 \%$ of the days. The hpp_1500MW_01b and hpp_1700MW_01 scenarios are in the same order, whereas the $E P_{99}$ in the eco_mgt scenario is only $602 \mathrm{MW}$. An operation rule targeting at an average electricity production of $1800 \mathrm{MW}$ leads to many failures in the simulations. For $\sim 3 \%$ of the days, no electricity production is simulated at all, because the active storage falls dry due to rather high release during the wet season.

Another interesting fact, clearly visible in Figure 8, is the impact of hydro-climatic conditions on the reliability of HPP, particularly in scenarios with low seepage rates. In wet periods, like in the 1960s and 1970s, there are either no or only a few events where HPP drops below the target in the hpp_1500MW_01 and hpp_1700MW_01 scenarios, whereas in the drier 1980s and 1990s, those events occur more frequently. With release rules targeting at a production of $1500 \mathrm{MW}$ and $1700 \mathrm{MW}$, a rather stable electricity generation could be achieved throughout the year. Assuming medium seepage rates, the average production is around $1300 \mathrm{MW}$ (Figure 9). 


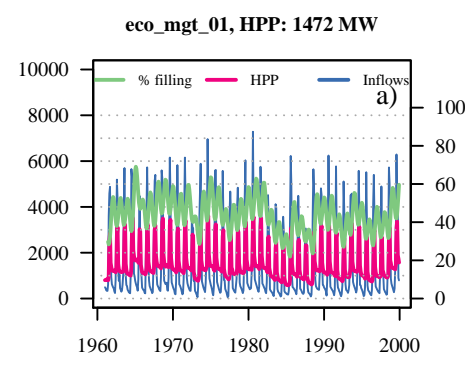

hpp_1500MW_01a, HPP: 1488 MW
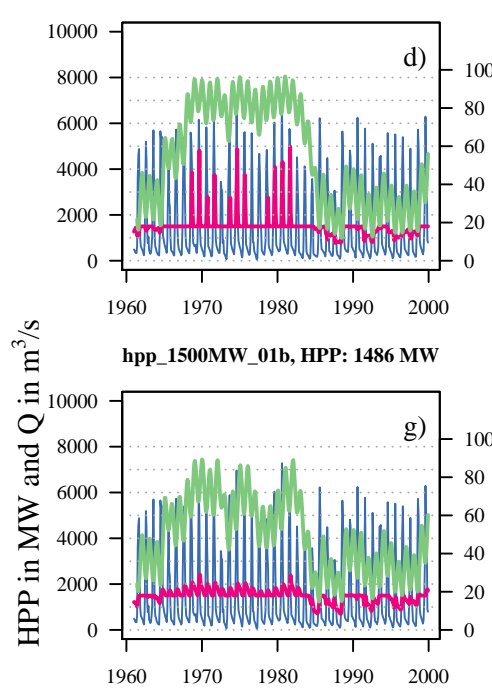

hpp_1700MW_01, HPP: 1449 MW

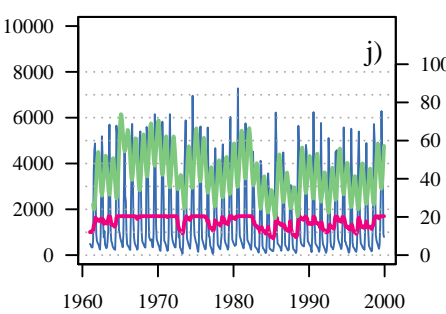

hpp_1800MW_01, HPP: 1288 MW

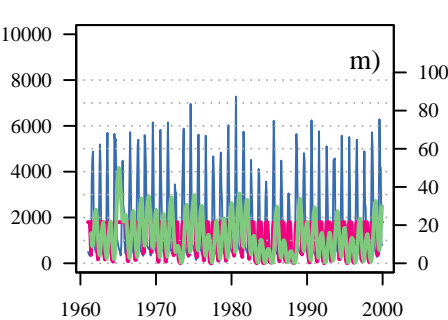

eco_mgt_02, HPP: 1327 MW

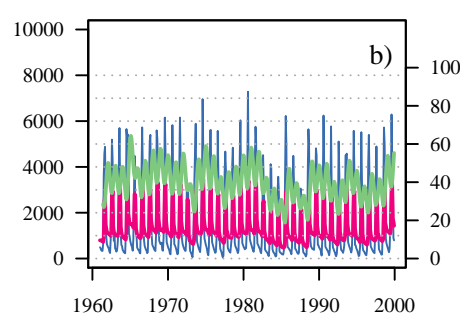

hpp_1500MW_02a, HPP: 1265 MW

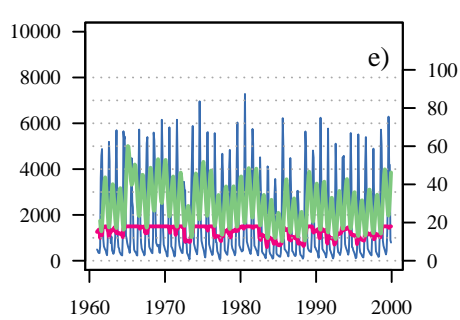

hpp_1500MW_02b, HPP: 1290 MW

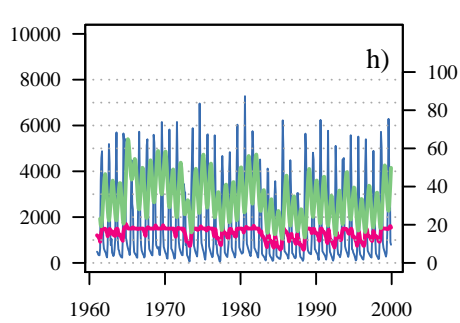

hpp_1700MW_02, HPP: 1305 MW

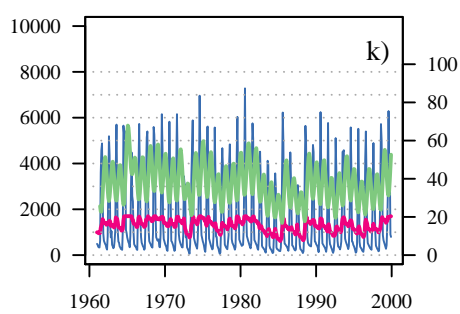

hpp_1800MW_02, HPP: 1217 MW

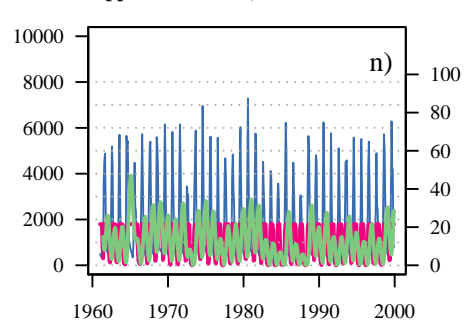

eco_mgt_03, HPP: 1049 MW

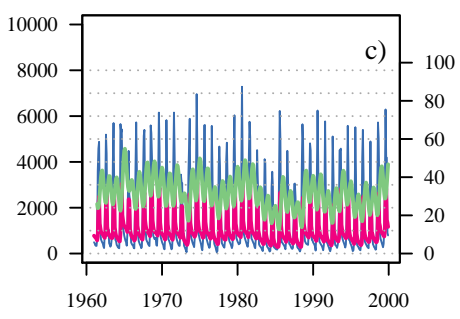

hpp_1500MW_03a, HPP: 1039 MW

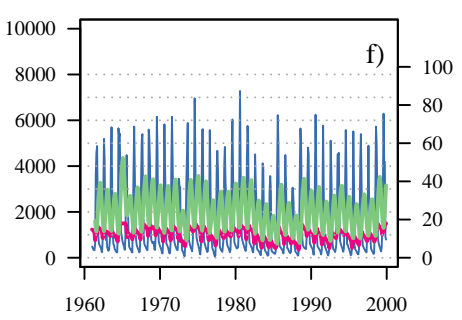

hpp_1500MW_03b, HPP: 1045 MW

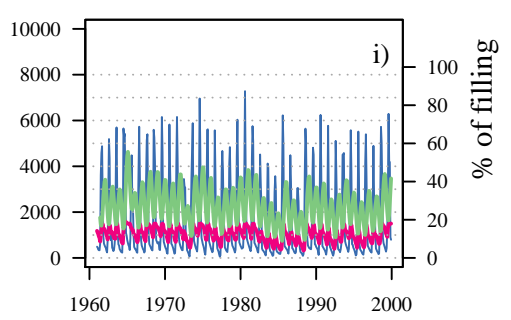

hpp_1700MW_03, HPP: 1037 MW

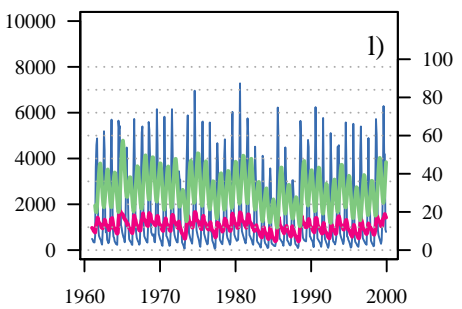

hpp_1800MW_03, HPP: 1070 MW

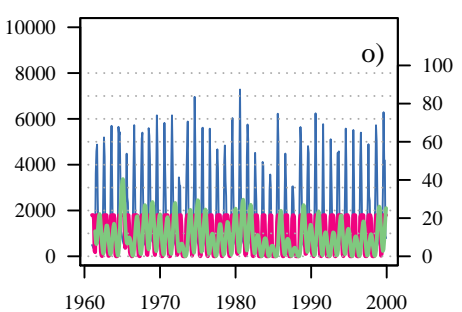

Figure 8. Reservoir filling, inflows and Hydroelectric Power Production (HPP) of all simulated operation scenarios under the reference climate using Watch Forcing Data (WFD). Rows represent the same management scenarios and columns seepage scenarios. Left $=$ "low", middle = "medium" and right $=$ "high" seepage rates.

The maximal simulated daily HPP value in the reference period is $5986 \mathrm{MW}$, which is almost the maximal capacity and only reached at FSL. The value exceeded in $10 \%$ of the days is between $1500 \mathrm{MW}$ and $1800 \mathrm{MW}$. Based on reference climate, the target of $15,692 \mathrm{GWh}^{-a}$ is never reached on average in the simulations, although it can be topped in extraordinary wet years. The maximal average annual simulated generation is $14,252 \mathrm{GWh}^{-a}$ ( $91 \%$ of the target) under wet hydro-climatic conditions 
between 1961 and 1980 in scenario hpp_1500MW_01a (see Table S3 in the Supplement). Under rather dry hydro-climatic conditions, as in the years between 1981 and 1999, the highest simulated average value is $11,793 \mathrm{GWh}^{-a}$ (75\% of the target); see Table $\mathrm{S} 4$ in the Supplement.

Figure S3 in the Supplement shows the reservoir filling, inflows and HPP using climate model input in the reference period and operation scenario hpp_1500MW_01a (low seepage rates). The ensemble mean of average HPP is in the same order as simulations based on WFD. However, the model spread is rather large (1050 MW-1695 MW). Most of the models provide comparable boundary conditions with wet and dry periods leading to highly variable inflows and storage filling states (as simulated with WFD). Exceptions are the HadGEM, MIROC and NorESM/RCA4 models that are characterized by lower filling variability and where FSL is never reached. The other models have a tendency toward a wet bias with higher inflows and consequently higher HPP.

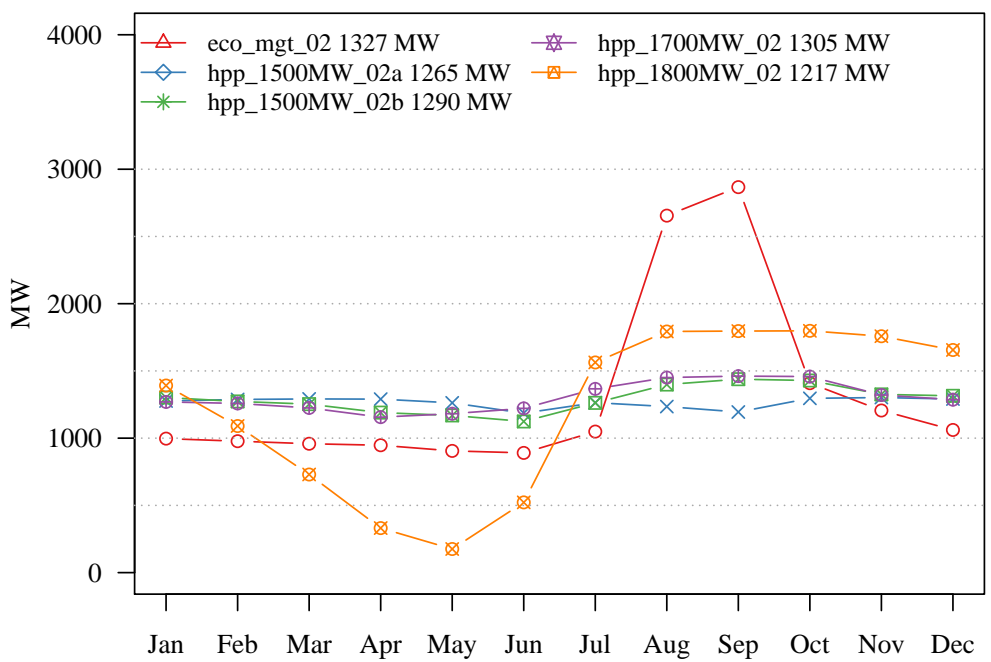

Figure 9. Average hydropower production during 1961-1999 with medium seepage rates.

\subsection{Climate Change Impacts}

As discussed in Liersch et al. (2016) [28], the characteristics and performance of discharge simulations using climate model input are diverse. Where non-extreme discharge conditions (between $Q_{20}$ and $Q_{80}$ ) are usually represented adequately in the reference period, particularly by models selected for this study, high and low flows, as well as their extremes are often overestimated or underestimated, respectively. As explained by Sippel et al. (2016) [37], such phenomena can result from deficiencies of bias-correction methods applied to climate model simulations, which do not adequately correct precipitation biases in higher and lower percentiles.

Relative to the historical period, the median of the ten climate models projects an increase in average annual precipitation by $54 \mathrm{~mm}^{-a}(+4 \%)$ in the near future and up to $70 \mathrm{~mm}^{-a}(+5 \%)$ in the far future. Average annual temperature may increase by $1.9 \mathrm{~K}$ in the period $2030-2059$ or by $4.5 \mathrm{~K}$ in the period 2070-2099 (see Table S5 and Figures S4 and S5 in the Supplement). As a consequence of increasing precipitation in the UBN, discharge simulations are projected to increase, as well, as was also shown by Liersch et al. (2016) [28] using an ensemble of (five ESMs and 10 RCMs) and two climate scenarios (RCP 4.5 and 8.5). It was also found that the models show a small shift in seasonality of discharges, with a drying trend in July slightly extending the dry season in the far future and a wetter trend between August and November.

Where the drying in July is not visible in simulated reservoir inflows and outflows (Figures 10 and 11), the wetter trend in the rainy season is clearly recognizable by comparing the dashed (historical) and dotted (future) lines. Both figures show results of the hpp_1500MW_01a scenario. The red lines, representing simulations based on WFD in the period 1970-1999, and the black 
dashed lines, representing the multi-model mean in the same period, show a very good match for all variables.

The ensemble range indicates that uncertainties related to climate model input can be rather large in the historical period. Mean annual inflows are in the range between $38 \mathrm{BCM}$ and $54 \mathrm{BCM}$, mean outflows between $36 \mathrm{BCM}$ and $52 \mathrm{BCM}$, mean reservoir evapotranspiration between 3.7 BCM and 4.0 BCM, and average annual HPP between 9190 GWh and 14,850 GWh. Unsurprisingly, the uncertainties of projections increase in time showing higher model ranges in the far future (2070-2099, Figure 11) than in the near future (2030-2059, Figure 10).

Table 5 shows average annual water balance parameters for $E T_{\text {Res }}$, Seep, precipitation onto the reservoir surface area $\operatorname{Pr}_{G E R D}$, the climatic water balance $C W B$, inflows and outflows and the hydropower results for mean HPP and exceedance probabilities $(E P)$ of HPP. The values are based on the hpp_1500MW_01a scenario assuming low seepage rates. They represent average simulation results based on WFD (1970-1999) and the climate model ensemble in the historical period (1970-1999), where numbers in brackets denote absolute changes between the far future (2070-2099) and the model's historical period. The values in columns "min", "mean", "median" and "max" represent the range of the model ensemble (averages of each model over the respective period). Average annual inflows (multi-model mean) are, for instance, projected to increase by $5 \mathrm{BCM}$ outbalancing the increasing losses from $E T_{\text {Res }}(0.1 \mathrm{BCM})$ and consequently leading to higher HPP yields $\left(+651 \mathrm{GWh}^{-a}\right)$. Note that the losses by $E T_{\text {Res }}$ in the historical period correspond to $8 \%$ of inflows, but rainfall onto the lake contributes $2.2 \mathrm{BCM}^{-a}$ resulting in a climatic water balance of $-1.6 \mathrm{BCM}^{-a}$ or $3.4 \%$ of average annual inflows. This fraction is not projected to change significantly in the future.

Table 5. Reservoir statistics comparison for WFD and model ensemble, hpp_1500MW_01a.

\begin{tabular}{|c|c|c|c|c|c|}
\hline & \multirow{2}{*}{$\begin{array}{c}\text { 1970-1999 } \\
\text { WFD } \\
\text { Mean }\end{array}$} & \multicolumn{4}{|c|}{$\begin{array}{c}\text { RCP } 8.5 \text { (2070-2099) } \\
\text { Climate Model Ensemble }\end{array}$} \\
\hline & & Min & Mean & Median & Max \\
\hline \multicolumn{6}{|l|}{ Water balance } \\
\hline$E T_{\text {Res }}\left(\mathrm{mm}^{-a}\right)$ & 5.6 & $4.9(-0.4)$ & $5.7(0.1)$ & $5.8(0.2)$ & $6.2(0.4)$ \\
\hline$E T_{\text {Res }}\left(\mathrm{BCM}^{-a}\right)$ & 3.8 & $3.4(-0.3)$ & $3.9(0.1)$ & $4.0(0.1)$ & $4.3(0.3)$ \\
\hline Seep $\left(\mathrm{BCM}^{-a}\right)$ & 0.2 & $0.1(0)$ & $0.2(0)$ & $0.2(0)$ & $0.2(0)$ \\
\hline $\operatorname{Pr}_{G E R D}\left(\mathrm{BCM}^{-a}\right)$ & 2.2 & $1.0(0)$ & $2.0(0)$ & $2.3(0)$ & $2.8(0.5)$ \\
\hline$C W B\left(\mathrm{BCM}^{-a}\right)$ & -1.6 & $-2.7(0)$ & $-1.9(-0.1)$ & $-1.8(-0.2)$ & $-1.3(0.2)$ \\
\hline Inflow $\left(\mathrm{BCM}^{-a}\right)$ & 47.2 & $38.9(0.6)$ & $52.9(5.0)$ & $50.1(0.4)$ & $83.5(29.9)$ \\
\hline Outflow $\left(\mathrm{BCM}^{-a}\right)$ & 45.4 & $36.7(1.2)$ & $50.8(4.9)$ & $47.7(0.4)$ & $81.9(30.2)$ \\
\hline \multicolumn{6}{|l|}{ Hydropower } \\
\hline $\mathrm{HPP}\left(\mathrm{GWh}^{-a}\right)$ & 12,921 & 9645 (451) & $13,384(651)$ & $13,399.8(-341)$ & $18,597(3750)$ \\
\hline EP_90 (MW) & 1086 & $412(-128)$ & $1121(1.1)$ & $1135(11)$ & $1499(0.6)$ \\
\hline EP_95 (MW) & 982 & $297(-87)$ & $933(-41)$ & $896(-50)$ & $1499(0.5)$ \\
\hline EP_99 (MW) & 800 & $177(-31)$ & $778(96)$ & $648(102)$ & $1497(36)$ \\
\hline
\end{tabular}

Note: Climate model ensemble values are calculated from model averages. Numbers in brackets denote absolute changes to the model's historical period (1970-1999).

However, the multi-model median shows a slightly different picture than the multi-model mean. The trends of the water balance parameters are similar, but less pronounced for inflows and outflows, which increase only by $0.4 \mathrm{BCM}^{-a}$ instead of $5 \mathrm{BCM}^{-a}$. Noticeably, HPP potentials decrease by $341 \mathrm{GWh}^{-a}$, although the absolute median value is still higher than the mean.

The state of reservoir filling, inflows and HPP over the simulation period 2020-2099 is shown for each climate model separately in Figure S6 in the Supplement. The simulations based on the ten climate models can show very different behavior in terms of inflow variability, impacting HPP and reservoir filling states. As in the reference period, the projections of all models indicate that future Blue Nile discharges are expected to be highly variable, with consecutive dry and wet years, but rather different 
lengths and magnitudes. Some simulations based on RCMs tend toward very extreme peak discharges accompanied by years with low discharges. Another phenomenon, which makes the interpretation of changes in time difficult, is that a wet period might be simulated by a couple of models, for instance in the period 2080-2099 (Figure S6d,f,g), whereas the same period is projected to be comparably dry by other models (Figure S6a,c,e,h).

Assuming a change of average annual HPP of $\pm 5 \%$ between the reference and future period to be not significant and all values below or above as negative or positive change, respectively, five models do not project significant changes, three models positive and two models negative changes in 2030-2059. In 2070-2099, only one model projects no significant change, six models positive change and three models negative change of HPP production. Speaking of a clear trend is thus not really justifiable although a slight tendency towards an agreement of higher HPP potentials exists, particularly in the far future (Figure S7 shows the ascending sorted annual HPP of each model in the three 30-years simulation periods).
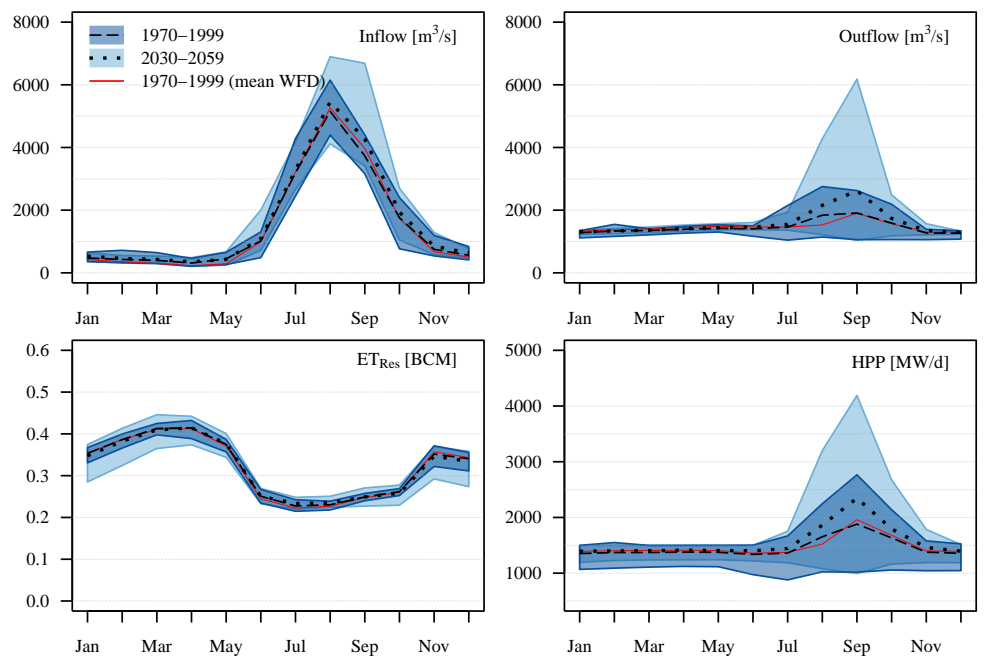

Figure 10. Range and mean of projected changes of inflows, outflows, $E T_{\text {Res }}$, and HPP using the model ensemble; RCP 8.5 (2030-2059), hpp_1500MW_01a scenario.
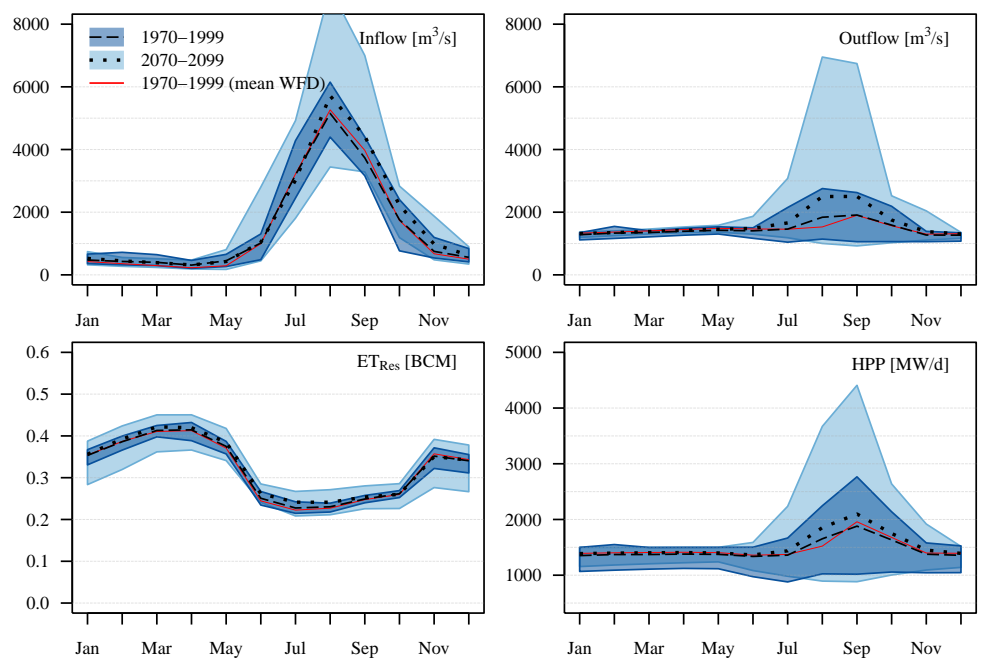

Figure 11. Range and mean of projected changes of inflows, outflows, $E T_{\text {Res }}$ and HPP using the model ensemble; RCP 8.5 (2070-2099), hpp_1500MW_01a scenario. 


\section{Discussion and Conclusions}

\subsection{Filling Scenarios}

The construction of the GERD at the Blue Nile River in Ethiopia will be finished in the coming years, and the process of reservoir filling will therefore start soon. According to the simulations conducted in this study, the filling of the dead storage DS with a capacity of 14.8 BCM may take at least half a year, but could endure up to about eight years. The final duration depends basically on filling strategies (minimal discharges to be released downstream), inflows (depending on hydro-climatic conditions during filling) and on losses from the reservoir due to evapotranspiration and seepage, where the latter are difficult to quantify. Where simulated evaporative losses during the filling process correspond to $6.5-8.7 \%$ of average annual inflows or $3.8 \mathrm{BCM}^{-a}$, seepage losses are negligible if assumed to be low, but could amount to $24-32 \%$ of inflows if assumed to be high. The contribution of rainfall onto the reservoir's surface area is not negligible and reduces the losses of $E T_{\operatorname{Res}}$ to $3.4 \%$ of average annual inflows, because the climatic water balance of the reservoir is $-1.6 \mathrm{BCM}^{-a}$.

Mulat and Moges (2014) [21] argue that there will be only a small impact during a six-year filling period on irrigation management of the High Aswan Dam (HAD) in Egypt. According to Whittington et al. (2014) [7], the filling of the GERD may adversely affect Egypt if it takes place in a sequence of dry years. In this case, the agricultural water demands might be higher than the water supply. Based on the results generated in this study, the reduction of Blue Nile flows during the filling process might be considerable, and Sudan and Egypt may face shortages of water supply. However, the severity of shortages will depend on filling strategies (minimal flows released) and hydro-climatic condition, such as rainfall in the Upper Blue Nile catchment, and the amount of storage losses via evapotranspiration and seepage. With a release rule that corresponds to monthly $Q_{50}$ discharges, the flows might be reduced by $10-19 \%$ compared to average flows during the reference period. Releasing discharges corresponding to $Q_{75}$ during the filling period may produce a drought that would normally occur every fourth year, and the reduction may be in the order of $16-44 \%$. To minimize the number of years with low discharges downstream, an alternative to these two scenarios could be a rule releasing monthly $Q_{25}$ discharges to fill the $D S$, taking up to almost eight years while cutting the flows by only $5-13 \%$ and changing the strategy under regular operation afterwards. This strategy would be in line with the assumption that water shortages in the range between $5 \%$ and $15 \%$ would be the maximum allowable amount for Egypt [15].

\subsection{Regular Operation and HPP}

The point in time when the GERD can start its regular operation depends on the targeted filling level of the active storage $A S$ and the same processes that apply to fill the $D S$. Based on the scenarios investigated in this study, the GERD may be taken into regular operation after less than two to five years assuming an operation level of $30 \%$ of the $A S$. In case the GERD starts operation when the $A S$ is half-full, it may take 2.5 years to almost nine years. Full supply level may be reached earliest after about four years assuming that monthly discharges released downstream correspond to $Q_{75}$ and low to medium seepage losses. With a release rule of $Q_{50}$, it may take up to 11 years or will never be reached at all if discharges corresponding to $Q_{25}$ are released, independently of the seepage rates. Simulated evaporative losses under regular operation are in the range between $7 \%$ and $8 \%$ of average annual inflows $\left(3.8 \mathrm{BCM}^{-a}\right)$ under reference climate conditions, corresponding to $5.6 \mathrm{~mm}^{-d}$ or $2044 \mathrm{~mm}^{-a}$. The volume evapotranspirating from the reservoir area under RCP 8.5 in 2070-2099 is projected by the ensemble mean to increase by $0.1 \mathrm{BCM}^{-a}$ with average daily evapotranspiration of $5.7 \mathrm{~mm}$ or $2080 \mathrm{~mm}^{-a}$ or by $0.2 \mathrm{BCM}^{-a}, 5.8 \mathrm{~mm}^{-d}$ and $2120 \mathrm{~mm}^{-a}$ if the ensemble median is considered. Regarding the increasing temperature (between 3.0 to $6.5 \mathrm{~K}$ ) at the end of the 21st Century [28], this is unexpectedly low. However, the model range is between $4.9 \mathrm{~mm}\left(1788 \mathrm{~mm}^{-a}\right)$ and $6.2 \mathrm{~mm}\left(2267 \mathrm{~mm}^{-a}\right)$. Note that the climatic water balance $C W B$ reduces the losses of $E T_{\text {Res }}$ considerably to $-1.6 \mathrm{BCM}^{-a}$. The $C W B$ projected by the model ensemble is in the range of $-1.3 \mathrm{BCM}^{-a}$ and $-2.7 \mathrm{BCM}^{-a}$ in 
2070-2099 and does not significantly change compared to the reference period. In the low seepage scenario, losses are almost negligible and are comparable to evaporative losses assuming medium seepage rates, but can amount to $\sim 25 \%$ assuming high seepage rates. The latter is controvertible, but was taken into consideration, because due to rock formations, Noureddin (2013) [13] assumes seepage losses of $25 \%$. Nevertheless, an unknown, but possibly large fraction may contribute to groundwater discharges downstream and would thus not necessarily be considered as a loss from the hydrological system, but as a loss for HPP.

According to the simulations investigated in this study, the GERD reservoir will be on average half-full, if it is operated similar to the $1500 \mathrm{MW}$ scenarios. Arjoon et al. (2014) [20] come to the same results, arguing that this is a trade-off between HPP and releasing flow regulation downstream. The exploitation of the reservoir capacity is much lower in the other scenarios. The risk that the AS runs dry is only observed in the 1800 MW scenarios, where the HPP target is obviously too high, causing frequently extreme low water levels in the dry season. It does not happen in any other scenario, not even under very dry conditions in the 1980s and assuming very high seepage losses. Arjoon et al. (2014) [20] found that the reservoir may completely drain under very dry conditions, where the "very dry conditions" were not precisely defined. This situation does not occur in the climate change $1500 \mathrm{MW}$ scenarios, although the models project a wide range of inflows and reservoir filling states, including a rather dry simulation (HadGEM, $1200 \mathrm{MW}$ ) and a rather wet simulation (EC-EARTH/RACMO $>1900 \mathrm{MW}$ ). The results confirm that an operation rule targeting at an average daily HPP of $1500 \mathrm{MW}$ is robust under various climatic conditions.

The maximum capacity of the power plants installed in the GERD will be $6000 \mathrm{MW}$ with the aim to produce $15,692 \mathrm{GWh}^{-a}$ [8]. This corresponds to a production of $1817 \mathrm{MW}$. According to Beyene (2013) [14], assuming average annual discharges of $1456 \mathrm{~m}^{3} \cdot \mathrm{s}^{-1}$, the dam will provide less than 2100 MW. In the study at hand, the HPP potential was investigated by analyzing five operation rules prioritizing different aims. From an economic perspective, the most likely and reasonable target is to generate reliable and constant hydropower throughout the year. This goal could be achieved due to the over-year storage capacity of the GERD. Basically, three operation scenarios with slightly different targets of HPP show that a constant supply of about 1200 MW-1700 MW (depending on the assumptions of seepage losses and climatic conditions) is theoretically possible throughout the year. Hence, even under optimistic conditions, the target is not reached under reference climate conditions, where $13,000 \mathrm{GWh}^{-a}$ are generated on average. In the RCP 8.5 climate scenario at the end of the 21st Century, the ensemble mean projects HPP potentials increasing by $650 \mathrm{GWh}^{-a}$, but the ensemble median a decrease by $340 \mathrm{GWh}^{-a}$. The model range, however, is rather large, where minimal average annual HPP is $\sim 9600 \mathrm{GWh}^{-a}$, and the maximum is $\sim 18,600 \mathrm{GWh}^{-a}$. Compared to the model's reference climate, the potentials increase by $450 \mathrm{GWh}^{-a}$ and $3750 \mathrm{GWh}^{-a}$ in the minimal and maximal averages, respectively.

An interpretation of changes in time is difficult, because some models project a wet period, for instance in the far future, whereas the same period is projected to be dry by other models. For example, three models project increasing, two models decreasing and five models no change in HPP potentials in the near future. In the far future, only one model projects no significant change, six models a positive and three models a negative trend for HPP.

\subsection{Impacts Downstream}

There seems to be no consensus in the literature on whether the GERD, once online, will more positively or negatively affect the downstream countries Sudan and Egypt. Some studies emphasize the potential negative impacts of the GERD on downstream discharges and that especially Egypt will suffer from lower hydroelectric power generation potential in the HAD and reduced revenues from irrigated agriculture [15,38,39]. Mulat and Moges (2014) [21] estimate a reduction of $7 \%$ in electricity generation of the HAD, once the GERD is online. Taye et al. (2016) [4] on the contrary argue that, with the GERD online, the minimum annual net benefit for Sudan and Egypt may increase from 
\$4.9-\$5.6 billion in the agricultural and energy sector. Besides greater net benefits with increasing storage in Ethiopia, floods and droughts will be reduced, and the hydrological uncertainties will be nullified, particularly during low flow periods [20]. The study at hand shows that the over-year storage capacity of the GERD may balance single drought years, but would not be able to buffer consecutive drought years. After such events, Egypt may run short of water, if GERD and HAD are not carefully coordinated [7]. A high level of cooperation, particularly during reservoir filling may significantly reduce the adverse affects on Sudan and Egypt [7,21].

Considering the large capacity of the reservoir, which could store approximately 1.5 years of long-term average discharges of the Upper Blue Nile River, and the fact that its main purpose is the generation of hydropower, the GERD will significantly alter the discharge regime downstream. Almost independent of how the dam will be operated, drastic impacts on the annual cycle of discharges can be expected, shifting from a strong seasonal to a completely balanced regime with almost constant discharges each month. Another effect is a reduction of the inter-annual and daily variability of discharges downstream. Years with high discharges will decrease, and years with low discharges will occur less frequently, although the latter depends on reservoir losses via seepage. Assuming medium to high seepage rates, years with low discharges will either remain unchanged, compared to the situation without GERD, or may increase, respectively.

Another option to operate the GERD is to release discharges by preserving the natural discharge regime in a certain way. Although the annual cycle would be smoothed considerably by increasing discharges by $100 \%$ (from $\sim 500-1000 \mathrm{~m}^{3} \cdot \mathrm{s}^{-1}$ ) during the dry season (November-May/June) and decreasing peak discharges in the rainy season by $30-70 \%$ (July-September), average annual HPP would only be a bit lower compared to operation rules prioritizing HPP. However, monthly HPP production would have a much higher variability, ranging from an average of $900 \mathrm{MW}$ in June to about $2800 \mathrm{MW}$ in September. If Ethiopia wants to realize its plans to play the role of a regional power hub by delivering reliable electric energy to neighboring countries, the deficits in months with low HPP would have to be balanced by other sources in such a management scenario, ideally by renewable sources like wind and solar power.

In any case, the downstream countries Sudan and Egypt have to be prepared to adapt to highly altered conditions. However, there will be opportunities and risks with regard to water management and ecosystem integrity. Sudan may benefit from regulated flows enabling the vast irrigated area (Gezira-Scheme) to be reliably supplied with water throughout the year, probably to the detriment of Egypt where water volumes entering the country would be further reduced in this case [7].

With regard to transboundary water management and water availability in the eastern Nile River basin, an interesting question is whether it makes sense to store water in regions with lower evaporative demand than in regions with higher evaporation rates. Shifting storage upstream would provide net water savings, because evaporation in the GERD is theoretically lower than in the HAD [7]. This would be particularly beneficial under projected climate change where temperature in the UBN may increase between 3.0 and $6.5 \mathrm{~K}$ at the end of the 21st Century compared to the period of 1970-1999 [28]. Due to the location of the GERD in a deep gorge, the surface area is relatively small compared to its volume, and the evaporative demand is lower than in the HAD [4]. Hence, water losses from evaporation in the GERD are much smaller than in the HAD [4]. Mean annual losses from both reservoirs, HAD and GERD, may be $16 \%$ less than the loss from the HAD operating alone [21]. As projected climate change adds another dimension of uncertainties on future water availability and its variability, since some models project higher other lower rainfall and discharges [40], water storages may represent another adaptation option allowing for coordinated responses to changing boundary conditions or extreme situations [7]. Ultimately, a win-win situation can only be achieved for all riparian countries, if a high level of cooperation in managing the Eastern Nile water resources were realized.

Supplementary Materials: The following are available online at www.mdpi.com/2073-4441/9/10/728/s1. Table S1: GERD data, Table S2: Climate models, Table S3: HPP statistics during operation (1961-1980); wet period, Table S4: HPP statistics during operation (1981-1999); dry period, Table S5: Average annual precipitation 
and temperature changes in the UBN projected by the climate model ensemble, Figure S1: GERD rule curves of the different operation scenarios, Figure S2: SWIM model performance in the 1960s and 1970s at gauge El Diem, Figure S3: Reservoir filling, inflows, and HPP simulated with climate model input in the reference period and operation scenario hpp 1500MW 01a (low seepage rate), Figure S4: Precipitation changes projected by the model ensemble, Figure S5: Temperature changes projected by the model ensemble, Figure S6: Operation scenarios under climate change projections and operation scenario hpp 1500MW 01a (low seepage rate), Figure S7: Sorted annual HPP in $\mathrm{TWh}^{-a}$ of the three 30-years periods and operation scenario hpp 1500MW 01a (low seepage rate), in brackets the mean annual production and in square brackets the change signal.

Acknowledgments: The research conducted in this study has received funding from the German Federal Foreign Office in the frame of adaptation to climate change in Ethiopia. The publication of this article was partially funded by the Open Access Fund of the Leibniz Association.

Author Contributions: S.L., H.K. and F.F.H. conceived and designed the experiments. H.K. parameterized the reservoir module and S.L. performed the experiments and analyzed the data. S.L. and H.K. wrote the paper.

Conflicts of Interest: The authors declare no conflict of interest.

\section{Abbreviations}

The following abbreviations are used in this manuscript:

$\begin{array}{ll}A S & \text { Active Storage } \\ \text { BC } & \text { Bias-Corrected } \\ \text { BCM } & \text { Billion Cubic Meters }\left(1 \mathrm{BCM}=1 \mathrm{~km}^{3}\right) \\ \text { CWB } & \text { Climatic Water Balance } \\ D S & \text { Dead Storage } \\ \text { ESM } & \text { Earth System Model } \\ E T_{a} & \text { Actual evapotranspiration } \\ E T_{p} & \text { Potential evapotranspiration } \\ E T_{\text {Res }} & \text { Evapotranspiration from the reservoir area } \\ \text { GERD } & \text { Grand Ethiopian Renaissance Dam } \\ \text { GHG } & \text { Greenhouse Gas Emissions } \\ \text { HAD } & \text { High Aswan Dam } \\ \text { HPP } & \text { Hydro Power Production } \\ \text { K } & \text { Kelvin } \\ \text { RCM } & \text { Regional Climate Model } \\ \text { RCP } & \text { Representative Concentration Pathway } \\ \text { UBN } & \text { Upper Blue Nile catchment } \\ \text { UC } & \text { Uncorrected } \\ \text { WFD } & \text { Watch Forcing Data }\end{array}$

\section{References}

1. ENREP. Electricity Network Reinforcement and Expansion Project: Project information Document. Available online: http://documents.worldbank.org/curated/en/806191468770728956/ pdf/PID0Appraisal0018201201334760889511.pdf (accessed on 21 September 2017).

2. Block, P.; Strzepek, K. Economic analysis of large-scale upstream river basin development on the Blue Nile in Ethiopia considering transient conditions, climate variability, and climate change. J. Water Resour. Plan. Manag. 2010, 136, 156-166.

3. Cuesta-Fernández, I. Mammoth dams, lean neighbours: Assessing the bid to turn Ethiopia into East Africa's powerhouse. In A New Scramble for Africa? Scholvin, S., Ed.; Ashgate: Farnham, UK, 2015; pp. 93-110.

4. Taye, M.T.; Tadesse, T.; Senay, G.B.; Block, P. The Grand Ethiopian Renaissance Dam: Source of cooperation or contention? J. Water Resour. Plan. Manag. 2016, 142, 02516001.

5. Global Water Forum (GWF). The Grand Ethiopian Renaissance Dam and the Blue Nile: Implications for Transboundary Water Governance. Available online: http://www.globalwaterforum.org/2013/ 02/18/the-grand-Ethiopian-renaissance-dam-and-the-blue-Nile-implications-for-transboundary-watergovernance/ (accessed on 21 September 2017). 
6. Gebreluel, G. Ethiopia's Grand Renaissance Dam: Ending Africa's oldest geopolitical rivalry? Wash Quart 2014, 37, 25-37.

7. Whittington, D.; Waterbury, J.; Jeuland, M. The Grand Renaissance Dam and prospects for cooperation on the Eastern Nile. Water Policy 2014, 16, 595-608.

8. International Panel of Experts (IPoE). Grand Ethiopian Renaissance Dam Project, Final Report. Available online: https:/ / www.internationalrivers.org/sites/default/files/attached-files/international_panel_of_ experts_for_ethiopian_renaissance_dam__final_report_1.pdf (accessed on 21 September 2017).

9. The Economist. The River Nile: A Dam Nuisance. Available online: http://www.economist.com/node/ 18587195 (accessed on 20 April 2011).

10. Nigatu, G.; Dinar, A. Economic and hydrological impacts of the Grand Ethiopian Renaissance Dam on the Eastern Nile River Basin. Environ. Dev. Econ. 2015, 21, 532-555.

11. Brookings. While Egypt Struggles, Ethiopia Builds over the Blue Nile: Controversies and the Way Forward. Available online: https://www.brookings.edu/blog/up-front/2013/07/25/while-egypt-struggles-ethiopiabuilds-over-the-blue-Nile-controversies-and-the-way-forward/ (accessed on 25 July 2013).

12. Financial Times. Nile Dam: Water Wars Averted for Now. Available online: https://www.ft.com/content/ 1f820ab2-b608-11e1-a511-00144feabdc0 (accessed on 19 June 2012).

13. Noureddin, N. Ethiopia's Catastrophic Dam. Available online: http://weekly.ahram.org.eg/News/3585. aspx (accessed on 21 September 2017).

14. Beyene, A. Ethiopia's Biggest Dam Oversized, Experts Say. Available online: https://www. internationalrivers.org/resources / ethiopia\%E2\%80\%99s-biggest-dam-oversized-experts-say-8082 (accessed on 10 October 2015).

15. Abdelhaleem, F.S.; Helal, E.Y. Impacts of Grand Ethiopian Renaissance Dam on different water usages in upper Egypt. Br. J. Appl. Sci. Technol. 2015, 8, 461-483.

16. International Rivers. GERD Panel of Experts Report: Big Questions Remain. Available online: https:/ / www.internationalrivers.org/gerd-panel-of-experts-report-big-questions-remain (accessed on 21 September 2017).

17. Zhang, Y.; Erkyihum, S.T.; Block, P. Filling the GERD: Evaluating hydroclimatic variability and impoundment strategies for Blue Nile riparian countries. Water Int. 2016, 41, 593-610.

18. Wheeler, K.G.; Basheer, M.; Mekonnen, Z.T.; Eltoum, S.O.; Mersha, A.; Abdo, G M.; Zagona, E.A.; Hall, J.W.; Dadson, S.J. Cooperative filling approaches for the Grand Ethiopian Renaissance Dam. Water Int. 2016, 41, 611-634.

19. Abdelhady, D.; Aggestam, K.; Andersson, D.E.; Beckman, O.; Berndtsson, R.; Palmgren, K.B.; Madni, K.; Ozkirimli, U.; Persson, K.M.; Pilesjo, P. The Nile and the Grand Ethiopian Renaissance Dam: Is there a meeting point between nationalism and hydrosolidarity? J. Contemp. Water Res. Educ. 2015, 155, 73-82.

20. Arjoon, D.; Mohamed, Y.; Goor, Q.; Tilmant, A. Hydro-economic risk assessment in the eastern Nile River basin. Water Resour. Econ. 2014, 8, 16-31.

21. Mulat, A.G.; Moges, S.A. Assessment of the impact of the Grand Ethiopian Renaissance Dam on the performance of the High Aswan Dam. J. Water Resour. Prot. 2014, 6, 583-598.

22. Jarvis, A.; Reuter, H.; Nelson, A.; Guevara, E. Hole-filled seamless SRTM data V4, International Centre for Tropical Agriculture (CIAT). Available online: http:/ / srtm.csi.cgiar.org (accessed on 5 April 2014).

23. Weedon, G.P.; Gomes, S.; Viterbo, P.; Shuttleworth, W.J.; Blyth, E.; Österle, H.; Adam, J.C.; Bellouin, N.; Boucher, O.; Best, M. Creation of the WATCH forcing data and its use to assess global and regional reference crop evaporation over land during the twentieth century. J. Hydrometeorol. 2011, 12, 823-848.

24. Uppala, S.M.; KÅllberg, P.W.; Simmons, A.J.; Andrae, U.; da Bechtold, D.C.; Fiorino, M.; Gibson, J.K.; Haseler, J.; Hernandez, A.; Kelly, G.A.; et al. The ERA-40 re-analysis. Q. J. R. Meteorol. Soc. 2005, 131, 2961-3012.

25. FAO; IIASA; ISRIC; ISSCAS; JRC. Harmonized World Soil Database (version .1). In FAO, Rome, Italy and IIASA, Laxenburg, Austria; 2009. Available online: http://www.fao.org/nr/land/soils/harmonized-worldsoil-database/en/ (accessed on 7 June 2014).

26. Bartholomé, E.; Belward, A.S. GLC2000: A new approach to global land cover mapping from Earth observation data. Int. J. Remote Sens. 2005, 26, 1959-1977.

27. Hempel, S.; Frieler, K.; Warszawski, L.; Schewe, J.; Piontek, F. A trend-preserving bias correction-The ISI-MIP approach. Earth Syst. Dynam. Discuss. 2013, 4, 49-92. 
28. Liersch, S.; Tecklenburg, J.; Rust, H.; Dobler, A.; Fischer, M.; Kruschke, T.; Koch, H.; Hattermann, F. Are we using the right fuel to drive hydrological models? A climate impact study in the Upper Blue Nile. Hydrol. Earth Syst. Sci. Discuss. 2016, 1-31, doi:10.5194/hess-2016-422.

29. Van Vuuren, D.; Edmonds, J.; Kainuma, M.; Riahi, K.; Thomson, A.; Hibbard, K.; Hurtt, G.C.; Kram, T.; Krey, V.; Lamarque, J.-F.; et al. The representative concentration pathways: An overview. Clim. Chang. 2011, 109, 5-31.

30. Krysanova, V.; Hattermann, F.; Wechsung, F. Development of the ecohydrological model SWIM for regional impact studies and vulnerability assessment. Hydrol. Process. 2005, 19, 763-783.

31. Arnold, J.G.; Allen, P.M.; Bernhardt, G. A comprehensive surface groundwater flow model. J. Hydrol. 1993, 142, 47-69.

32. Krysanova, V.; Meiner, A.; Roosaare, J.; Vasilyev, A. Simulation modelling of the coastal waters pollution from agricultural watershed. Ecol. Model. 1989, 49, 7-29.

33. Krysanova, V.; Hattermann, F.; Huang, S.; Hesse, C.; Vetter, T.; Liersch, S.; Koch, H.; Kundzewicz, Z.W. Modelling climate and land use change impacts with SWIM: Lessons learnt from multiple applications. Hydrol. Sci. J. 2015, 60, 606-635.

34. Wendling, U.; Schellin, H.-G.; Thomä, M. Bereitstellung von täglichen Informationen zum Wasserhaushalt des Bodens für die Zwecke der Agrarmeteorologischen Beratung. Z. Meteorol. 1991, 41, 468-475 (In German).

35. Koch, H.; Liersch, S.; Hattermann, F. Integrating water resources management in eco-hydrological modelling. Water Sci. Technol. 2013, 67, 1525-1533.

36. Nash, J.E.; Sutcliffe, J.V. River flow forecasting through conceptual models, part $1-$ A discussion of principles. J. Hydrol. 1970, 10, 282-290.

37. Sippel, S.; Otto, F.E.L.; Forkel, M.; Allen, M.R.; Guillod, B.P.; Heimann, M.; Reichstein, M.; Seneviratne, S.I.; Thonicke, K.; Mahecha, M.D. A novel bias correction methodology for climate impact simulations. Earth Syst. Dyn. 2016, 7, 71-88.

38. Ahmed, A.T.; Elsanabary, M.H. Hydrological and environmental impacts of Grand Ethiopian Renaissance Dam on the Nile River. In Proceedings of the Eighteenth International Water Technology Conference, IWTC18, Sharm El Sheikh, Egypt, 12-14 March 2015.

39. Chen, H.; Swain, A. The Grand Ethiopian Renaissance Dam: Evaluating its sustainability standard and geopolitical significance. Energy Dev. Front. 2014, 3, 11-19.

40. Teklesadik, A.D.; Alemayehu, T.; van Griensven, A.; Kumar, R.; Liersch, S.; Eisner, S.; Tecklenburg, J.; Ewunte, S.; Wang, X. Inter-model comparison of hydrological impacts of climate change on the Upper Blue Nile basin using ensemble of hydrological models and global climate models. Clim. Chang. 2017, $141,517-532$.

(C) 2017 by the authors. Licensee MDPI, Basel, Switzerland. This article is an open access article distributed under the terms and conditions of the Creative Commons Attribution (CC BY) license (http:// creativecommons.org/licenses/by/4.0/). 